\title{
Currency Mismatch, Openness and Exchange Rate Regime Choice
}

\author{
Nicolas E. Magud* \\ University of Oregon
}

This draft: September 2004

First draft: December 2002

\begin{abstract}
The paper analyzes the choice of an exchange rate regime for a small open economy indebted in foreign currency, incorporating the financial accelerator. Conventional wisdom suggests that floating regimes should insulate the economy from real shocks. I show that this result depends on the degrees of openness of the economy and foreign currency indebtedness and, in fact, does not hold for relatively closed economies. The transmission mechanism relies on nonlinearities in the impact of unanticipated real price changes on the external finance premium, in the spirit Fisher (1933).
\end{abstract}

Keywords: Currency Mismatch; Liability Dollarization; Balance Sheets; Exchange Rate Regimes; Openness; Nominal Rigidities.

JEL Classification: E31; E32; F34; F41.

\footnotetext{
*Department of Economics, University of Oregon, Eugene, OR 97403-1285, USA. Email: magud@uoregon.edu. This paper is based on chapter 2 of my Ph.D. thesis at University of Maryland. I thank Leopoldo Avellan, Marco Arena, Roger Betancourt, Michael Binder, Fernando Broner, Robert Flood, Federico Guerrero, Sergio Kurlat, Enrique Mendoza, Mike Pries, Carmen Reinhart, Pedro Rodriguez, Sergio Schmukler, John Shea, Lars Svensson, Juan Treviño, Esteban Vesperoni, and seminar participants at 2003 Lacea $8^{\text {th }}$ Annual Meetings (Puebla, Mexico), Bank of England, University of Oregon, University of Maryland, Universidad de Alicante, and the Interuniversity Economics Graduate Students Seminars at Yale and Columbia for insightful comments, suggestions and stimulating conversations out of which this product emerged. Finally, I would also like to thank Paul Cashin and Carmen Reinhart for providing me with all the necessary data for the empirical analysis. All remaining errors are mine.
} 


\section{Introduction}

This paper analyzes the choice of an exchange rate regime for a small open economy indebted in foreign currency, incorporating the financial accelerator. Conventional wisdom suggests that floating regimes should insulate the economy from real shocks. I show that this result depends on the degrees of openness of the economy and foreign currency indebtedness and, in fact, does not hold for relatively closed economies. The transmission mechanism relies on nonlinearities in the impact of unanticipated real price changes on the external finance premium, in the spirit Fisher (1933).

Magud (2003b) documents that the output response to real shocks depends on the degree of openness of the economy - see Figure 1. For foreign-currency indebted countries, relatively open economies tend to be better insulated from real shocks (in terms of output dynamics) when they are under a flexible exchange rate regime. However, relatively closed economies are able to buffer the real shock better if they are ruled by a fixed regime.
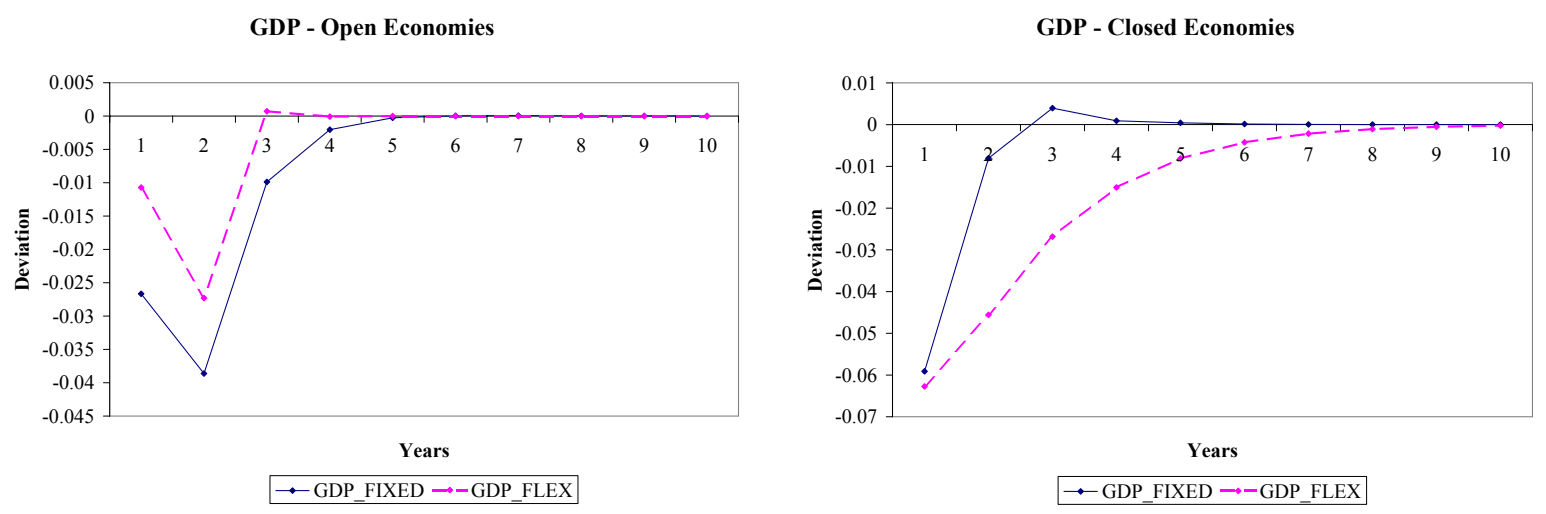

Figure 1: Impulse Response for relatively open economies (left panel) and relatively closed economies (right panel) in presence of fixed and flexible exchange rate regimes.

Thus, the core contribution of this paper focuses on explaining why the choice of the exchange rate regime should be contingent on the degree of openness of the economy and the degree of currency mismatch. Specifically, in response to real shocks such as terms of trade, international interest rate or export demand shocks, some countries will be better served by fixed regimes, whereas some others will be better off with flexible arrangements. Determining which exchange rate to choose will depend on the share of non-tradable goods in aggregate output and the ratio of the foreign-currency-denominated debt to total debt. To do it, I build a Stochastic Dynamic General Equilibrium (SDGE) model with nominal rigidities, financial frictions and foreign-currencydenominated debt to explain these stylized facts. Using this framework, the specific contributions of this paper are the following:

First, I show that the differentiated performance of alternative exchange rate regimes stems 
from the output composition of domestic goods: the higher the share of tradables in GDP (i.e., the higher the degree of openness of the economy), the higher the likelihood that a flexible exchange rate regime will perform better as a shock absorber. Conversely, the more closed to trade an economy is, the more likely that a fixed regime will be the optimal choice.

The intuition behind this result is explained as follows. Entrepreneurs (borrowers) pay an external finance premium that is increasing in their leverage. If a real devaluation results from a negative real shock, the former generates a jump in the real value of debt: the balance sheet effect. For producers of tradables, the expansionary effects of the real devaluation compensate the contractionary balance sheet effect. However, non-tradables are negatively affected in their balance sheets but lack a "rest of the world" which they can re-direct the excess supply generated by the fall in domestic demand. This reduces revenues - both prices and quantities fall - and consequently reduces the ability of entrepreneurs to purchase the necessary capital for future production. This also generates an intertemporal link, due to the increased external finance premium that results from a higher leverage, which reduces the ability to purchase capital in the future. Furthermore, since the reduction in the demand for capital reduces the equilibrium price of capital, this reduces current net worth further as well as future net worth - thus exacerbating the intertemporal propagation and therefore the external finance premium.

As a result of this process, some sectors of the economy benefit with a flexible exchange rate, whereas some others would be better served by a peg. Thus, the selection of the exchange rate regime hinges on the weight that each of these sectors has within the aggregate economy.

Second, I extend Irving Fisher's debt-deflation theory for open economies. If the ex-post real return to capital or the ex-post real devaluation ends up being different than expected, the external finance premium that entrepreneurs pay on loans increases in a nonlinear fashion. The greater the currency mismatch is when the real price changes, the greater the increase in the premium that entrepreneurs pay on their external borrowing. It is shown that this is because the elasticity of the risk premium with respect to unanticipated devaluations (as well as to real return to capital changes) is increasing in the level of leverage at the moment the shock occurs. In this sense, small unexpected shocks to the economy get amplified and propagate, thus generating economic fluctuations at business cycles frequencies. ${ }^{1}$ Furthermore, as before, this affects the non-tradable sector more than the tradable sector.

The above mentioned nonlinearity raises the question of whether it is always welfare improving for an economy to pay for the cost of a negative shock at the outset of the crises, or if it might be better to spread out its effect along time, so as to smooth the business cycle - by dampening the multiplier effects over time. This opens a discussion whether to experience a "Short-Sharp" or a

\footnotetext{
${ }^{1}$ In Fisher (1933), the original problem was the output overreaction due to credit market imperfections: given low interest rates, many unprofitable projects were carried on, displaying high prices and therefore driving the economy to a level of investment above the natural rate. Once the overoptimistic behavior revealed incorrect, so did the over-borrowing, so prices started dropping. This increased the real value of firms' debts while decreased their revenues and made many of them to become insolvent and going bankrupt. Thus, due to the misperceived expected profits, when the state of nature revealed itself, the necessary adjustment to return the economy to its long run equilibrium is amplified.
} 
"Long-Mild" recession. In this respect, the third contribution is to analyze how this choice depends on the degree of openness and degree of currency mismatch, and what are the policy implications therein. Under some situations, it is more costly for the economy to bear the burden of a shock on impact than to smooth it out. However, the more open an economy is, the lower the costs of paying for the shock on impact instead of spreading it over time. The intuition for this parallels the benefits from smoothing in the presence of convex adjustment cost. Whether to do bunching or smoothing of the "welfare" costs associated with the response to a real shock will depend on the trade-offs generated by the ratio of non-tradables to GDP and the currency composition of debt.

The conclusion of the paper is that when focusing on the determination of an exchange rate for a small open economy mainly affected by real shocks, the degree of openness of the economy plays an important role, especially when balance sheet effects are present and nominal rigidities exist. The driving force operates through the nonlinearity of the external finance premium response to unanticipated changes in the real price of capital or unanticipated real devaluations. The higher the leverage when unexpected real price change occurs, the larger the observed increase in the external finance premium. Furthermore, and unlike the conventional wisdom from Friedman (1953), small open economies will not always benefit from a flexible exchange rate regime. Only to the extent that they are sufficiently open will these economies be better off with flexible regimes. For relatively closed economies, fixed regimes are better real shock absorbers.

The paper is organized as follows. Section (2) discusses how this paper fits in the existing literature. Section (3) describes the general equilibrium model, including nominal rigidities, currency mismatch and the balance sheet effect. Section (4) shows the intrinsic nonlinear relationship between unanticipated changes in real prices and the risk premium, as well as its effect on the economy conditional on the degree of foreign currency indebtedness and the degree of openness. Section (5) analyzes the impulse response of the economy to real shocks, controlling for the degree of openness of the economy, and presents the main results of the paper. It also discusses the policy implications. Finally, Section (6) concludes and suggest some extensions.

\section{Related Literature}

Conventional wisdom, which goes back at least to Meade (1951) and Friedman (1953), states that in the presence of nominal rigidities, flexible exchange rates are to be preferred in countries that are mostly exposed to real shocks. The rationale for this argument is that the exchange rate will accommodate the required change in relative prices that domestic prices are temporarily unable to do by themselves, thus dampening real effects. On the contrary, in the presence of a fixed exchange rate, the real side of the economy will bear the burden of the adjustment (e.g., a recession in case of a negative terms of trade shock) so as to make relative prices progressively and costly adapt to the new equilibrium.

Mundell (1960) extends this argument to analyze Optimal Currency Areas. Small open economies affected by asymmetric real shocks should establish fixed exchange rate regimes to reduce real ex- 
change rate volatility. The latter, in turn, reduces output volatility; in this sense, the higher the degree of openness, the more responsive output is to fluctuations in the real exchange rate. Poole (1970) shows that for small open economies mainly affected by real shocks, flexible exchange rates outperform fixed regimes, whereas the opposite is true for economies more exposed to nominal shocks.

However, and especially since the Asian crisis of 1997, some writers have articulated different views. $^{2}$ At the time of the collapse, entrepreneurs in most developing countries were under a currency mismatch: debts were in foreign currency - mainly in dollars, thus giving rise to the common terminology of liability dollarization ${ }^{3}$ - while sales were usually priced in domestic currency. This gives a salient role to the balance sheet (or credit) channel: if the economy is unexpectedly "forced" into a real depreciation, the burden of debt will instantaneously jump while revenues, at best, will remain constant in domestic currency. Consequently, entrepreneurs' net worth will be reduced, many firms will be unable to repay their debts and will go bankrupt; and output will decrease because of the decreased ability of firms to raise funds to finance the purchase of additional capital.

In response to this, some models introduce balance sheet effects in a general equilibrium setting with nominal rigidities (e.g. Céspedes, Chang and Velasco (2001a, 2001b and 2001c), CCV henceforth, or Gertler, Gilchrist and Natalucci (2001)), and claim that (Friedman's) conventional wisdom is still valid. In these models, the expansionary effects of the real depreciation offset the contractionary balance sheet effects generated by the currency mismatch. This implies that floats should be preferred to fixed regimes in order to absorb real shocks. Moreover, CCV claim that although a possible theoretical construct, the balance sheet effect can not offset the expansionary effects of depreciations unless unrealistic assumptions on parameter values are considered. ${ }^{4}$

At the empirical level the evidence is mixed. On the one hand, Broda (2000), Edwards and LevyYeyati (2002) and Levi-Yeyati and Sturzenegger (2001a and 2001b) present evidence consistent with flexible exchange rate regimes being better than fixed regimes - in terms of output response - in absorbing terms of trade shocks. On the other hand, Calvo and Reinhart (2000 and 2002), Calvo, Izquierdo and Talvi (2002), Hausmann, Gavin, Pages-Serra and Stein (1999), Devereux (2001), as well as Hausman, Panizza and Stein (2000), document that the output effects of real shocks are larger in countries with flexible exchange rate regimes when compared with countries that fix their exchange rate. ${ }^{5}$

However, Magud (2003b) sheds some light on this: using a panel VAR, it shows that the choice of an exchange rate regime - in order to smooth output fluctuations in response to a terms of trade

\footnotetext{
${ }^{2}$ See e.g. Krugman (1999) and Calvo (1999).

${ }^{3}$ Theoretical explanations of these patterns in terms of rational forward looking environments have been put forward, among others, by Caballero and Krishnamurthy (2000) and Jeanne (2001).

${ }^{4}$ In Gertler, Gilchrist and Natalucci (2001) the argument is somewhat different. They introduce a standard Taylor rule in which the domestic interest rate responds to changes in output, inflation and prices and the expansionary channel emerges out of the decrease in the nominal interest rate as a response to the real shock.

${ }^{5}$ Interestingly, Hausmann, Gavin, Pages-Serra and Stein (1999) show that the response of the economy to real shocks is nonlinear, in line with section (4) below.
} 
shock - depends on the degree of openness of the economy. Thus, the documented evidence implies that there are some cases under which flexible exchange rates are better absorbers of real shocks, whereas in other situations fixed regimes perform better. This is precisely the point that this paper addresses. It identifies characteristics of SOE's, such as the degree of openness and the degree of currency mismatch, that strongly affect the output response of the economy to real shocks. In turn, it explains how the choice of the exchange rate regime is contingent on these characteristics.

\section{Model Economy}

\section{$3.1 \quad$ Model Outline}

The model belongs to the class of Dynamic New Keynesian models for open economies. The set up is a standard consumers/workers general equilibrium economy composed of tradable goods and non-tradable goods firms, with entrepreneurs and capital producers in both sector, and a rest of the world. The Figure A.I in the appendix displays the interconnection of the different agents in the economy.

Wages are sticky and debt is denominated in foreign currency (dollars) in the context of a small open economy (i.e. international prices are given). Capital purchased in period $t$ is used to produce during period $t+1$ after which it depreciates in full.

Workers consume a CES composite of tradable and non-tradable goods. The former, in turn, is a CES composite of tradables produced either domestically (home goods) or internationally (foreign goods). Consumers receive income from working in the home goods (tradable) sector and in the non-tradable goods sector. Workers demand the three goods such that the relative demand of each good depends negatively on its relative price. Also, labor supply to each sector is positively related to the real wage.

Firms produce in a competitive environment, maximizing profits subject to their budget constraints. This results in standard demand functions for capital and labor, in which marginal benefit equals marginal cost.

Capital producers, which for simplicity are assumed to be sector-specific, purchase output from firms at the end of period $t$ and sell capital that firms will use to produce output during period $t+1$ by way of a concave production function to account for adjustment costs.

Entrepreneurs are the key players in this model. We assume that they are the only type of individuals that can borrow and that they are able to do it only in international markets; moreover, this borrowing is done in foreign currency. Specifically, and following the literature initiated by Kiyotaki and Moore (1997) and extended, among others, by Bernanke, Gertler and Gilchrist (2000), we assume that entrepreneurs lack enough funds out of their after-consumption net worth to purchase capital; furthermore, this constraint is always binding. ${ }^{6}$ Also, this makes the endogenous external finance premium positively related to the entrepreneur' s leverage and

\footnotetext{
${ }^{6}$ See Mendoza (2001) for the case in which this constraint is endogenously not always binding in the context of a small open economy.
} 
implies that for an entrepreneur to be able to increase investment in a firm - given its net worth (i.e. increasing its leverage), expected profitability of the project should compensate for the extra financial premium to be paid. This mechanism is usually known as a financial accelerator.

Let's summarize the model's interactions among the different agents. In each sector, capital producers, purchase output to produce capital that will be used the following period. Entrepreneurs add their borrowing in the rest of the world to their net worth to purchase capital from capital producers. This capital is then rented to firms. In turn, the latter also hire workers. These workers, which work for each sector earn a wage that is used for the consumption of the non-traded good, the domestic traded good and the foreign good. Entrepreneurs, for simplicity, are assumed to consume foreign goods only. The diagram in the appendix reflects all the mentioned interactions.

In the context of this set up, the exercise consists in analyzing the economy's dynamics in response to real shocks under different exchange rate regimes and to look for the benefits and costs of each monetary arrangement depending on specific country characteristics such as the degree of openness (denoted by the share of non-tradables in aggregate output) and the degree of currency mismatch (reflected in the degree of foreign-currency-denominated debt).

\section{$3.2 \quad$ Firms}

In the domestic economy, a unit mass of home tradables $(\mathrm{H})$ and a unit mass of non-tradables $(\mathrm{N})$ - or in general $J=H, N$ - firms are perfectly competitive within each sector and produce $Y_{t}^{J}$ units in period $t$ using a Cobb-Douglas technology in which factors of production are capital rented in period $t$ (produced during period $t-1), K_{t-1}^{J}$, and labor hired in $t, L_{t}^{J}$ :

$$
Y_{t}^{J}=A_{t}^{J}\left(K_{t-1}^{J}\right)^{\alpha^{J}}\left(L_{t}^{J}\right)^{1-\alpha^{J}}
$$

where $A_{t}^{J}$ represents a technology shifter and $\alpha^{J} \in(0,1)$ accounts for the share of capital in output in sector $J$. It is worth noting that the aggregate capital stock is pre-determined, since entrepreneurs that own capital - see below - decide in period $t-1$ how much capital to purchase in order to rent it during period $t$. However, individual firms decide how much capital to hire during period $t$, but they do not pre-commit to a capital stock at period $t-1$. Instead, firms bid up the rental price of capital so that the market for capital clears.

Labor within each sector is composed of a continuum of workers in the unit interval, indexed by $i$, that are assumed to behave in a monopolistic competitive fashion in the sense of Dixit and Stiglitz (1977). ${ }^{7}$ Aggregate labor in sector $J$ equals

$$
L_{t}^{J}=\left[\int_{0}^{1}\left(L_{i t}^{J}\right)^{\frac{\sigma-1}{\sigma}}\right]^{\frac{\sigma}{\sigma-1}}
$$

where $\sigma$ is the intratemporal elasticity of demand for worker $i$ during period $t$ in sector $J$.

\footnotetext{
${ }^{7}$ This assumption is explicitly introduced to generate nominal rigidities in the labor market.
} 
Firms optimization problem consists in maximizing profits subject to hiring factors of production, as follows

$$
\max _{\left\{K_{t}^{J}, L_{t}^{J}\right\}} \pi_{t}^{J}=P_{t}^{J} A_{t}^{J}\left(K_{t-1}^{J}\right)^{\alpha^{J}}\left(L_{t}^{J}\right)^{1-\alpha^{J}}-R_{t}^{J} K_{t-1}^{J}-\int_{0}^{1} W_{i t}^{J} L_{i t}^{J} d i
$$

for a rental rate of capital in sector $J$ during period $t$ equal to $R_{t}^{J}$, and paying a wage rate equal to $W_{i t}$ to worker $i$ during period $t$. The price index in sector $J$ during period $t$ is $P_{t}^{J}$. Notice that the minimum cost of a unit of labor in sector $J$ at time $t$ thus equals

$$
W_{t}^{J}=\left[\int_{0}^{1} W_{i t}^{1-\sigma} d i\right]^{\frac{1}{1-\sigma}}
$$

First order conditions are obtained by equalizing marginal benefit with marginal cost and display demand for both factors of production that are negatively dependent on their real cost.

$$
\begin{gathered}
\frac{R_{t}^{J}}{P_{t}^{J}}=\frac{\alpha^{J} Y_{t}^{J}}{K_{t-1}^{J}} \\
\frac{W_{t}^{J}}{P_{t}^{J}}=\frac{\left(1-\alpha^{J}\right) Y_{t}^{J}}{L_{t}^{J}}
\end{gathered}
$$

Also, notice that cost minimization implies that demand for worker $i$ will be equal to

$$
L_{i t}^{J}=\left(\frac{W_{i t}^{J}}{W_{t}^{J}}\right)^{-\sigma} L_{t}^{J}
$$

In equilibrium firms will make zero profits.

\subsection{Consumers/Workers}

We consider a small open economy where atomistic consumers (workers), indexed by $i \epsilon[0,1]$, consume non-tradables $(\mathrm{N})$ and tradables $(\mathrm{T})$. In turn, the latter are either home produced $(\mathrm{H})$ or produced in foreign countries (F). Also, consumers supply labor to both domestic sectors, home and non-tradables. Specifically, each worker consumes a basket of tradables and non-tradables given by a CES aggregator with shares $\gamma$ and $(1-\gamma)$, respectively, as follows

$$
C_{i t}=\left[\gamma^{\frac{1}{\rho}}\left(C_{i t}^{T}\right)^{\frac{\rho-1}{\rho}}+(1-\gamma)^{\frac{1}{\rho}}\left(C_{i t}^{N}\right)^{\frac{\rho-1}{\rho}}\right]^{\frac{\rho}{\rho-1}}
$$

where $C_{i t}$ is the level of consumption of individual $i$ in period $t, C_{i t}^{T}$ represents consumption of tradables of individual $i$ during period $t, C_{i t}^{N}$ is consumption of non-tradables of individual $i$ in $t$ and $\rho$ denotes the intratemporal elasticity of substitution between tradables and no-tradables.

Similarly, consumption of tradables in period $t$ is also a CES aggregator of Home goods, $C_{i t}^{H}$, and Foreign goods, $C_{i t}^{F}$, with shares $\phi$ and $(1-\phi)$, respectively, given by 


$$
C_{i t}^{T}=\left[\phi^{\frac{1}{\varsigma}}\left(C_{i t}^{H}\right)^{\frac{\varsigma-1}{\varsigma}}+(1-\phi)^{\frac{1}{\varsigma}}\left(C_{i t}^{F}\right)^{\frac{\varsigma-1}{\varsigma}}\right]^{\frac{\varsigma}{\varsigma-1}}
$$

where $\varsigma$ denotes the intratemporal elasticity of substitution between home and foreign tradables.

Since each worker is infinitesimally small and all act alike, aggregation in equilibrium becomes straightforward, so that subscript $i$ can be obviated henceforth.

The consumption indexes imply that the minimum cost of purchasing these baskets will be given by the price indices

$$
\begin{aligned}
& P_{t}=\left[\gamma\left(P_{t}^{T}\right)^{1-\rho}+(1-\gamma)\left(P_{t}^{N}\right)^{1-\rho}\right]^{\frac{1}{1-\rho}} \\
& P_{t}^{T}=\left[\phi\left(P_{t}^{H}\right)^{1-\varsigma}+(1-\phi)\left(P_{t}^{F}\right)^{1-\varsigma}\right]^{\frac{1}{1-\varsigma}}
\end{aligned}
$$

where $P_{t}$ corresponds to the aggregate economy's price index in period $t, P_{t}^{T}$ reflects the price of tradables during $t, P_{t}^{N}$ is the price on non-tradables, and $P_{t}^{H}$ and $P_{t}^{F}$ are the prices, during period $t$, of home and foreign goods, respectively.

Assume that the law of one price holds along with free trade, thus implying that the domestic price of home goods equals the foreign price of home goods times the exchange rate, and that the domestic price of the foreign good equals the exchange rate times the foreign price of the foreign good:

$$
\begin{aligned}
& P_{t}^{H}=S_{t} P_{t}^{H *} \\
& P_{t}^{F}=S_{t} P_{t}^{F *}
\end{aligned}
$$

where the nominal exchange rate in period $t$, defined as the domestic price of foreign currency in terms of domestic currency, is given by $S_{t}$, and an asterisk denotes the international counterpart of any variable.

For the sake of simplicity we normalize $P_{t}^{F *}=1 \forall t$, and $\frac{P_{t}^{H *}}{P_{t}^{F *}}$ will equal one in steady state.

Moreover, we have already assumed that workers are monopolistically competitive within each sector in the sense of Dixit and Stiglitz (1977), thus allowing for nominal rigidities in the labor market; the latter will come from wage setting. ${ }^{8}$ Following the standard Dynamic New Keynesian literature, we assume that workers can only adjust their wages randomly, according to the Calvo (1983) mechanism. Each period, a fraction $(1-\theta)$ of workers in sector $J$ are able to re-set their wages to $\overline{W_{t}^{J}},{ }^{9}$ independently of the last time of adjustment, thus implying that the expected time until a new adjustment is $\frac{1}{1-\theta}$. As a result, the wage index in period $t$ becomes,

\footnotetext{
${ }^{8}$ Results are qualitative similar if instead we impose price stickiness.

${ }^{9}$ Notice that since individuals behave symmetrically, every individual that adjusts her wage will do it to the same level $\overline{W_{t}^{J}}$, independently of what others are doing.
} 


$$
W_{t}^{J}=\left[\theta\left(W_{t-1}^{J}\right)^{-\kappa}+(1-\theta)\left(\overline{W_{t}^{J}}\right)^{-\kappa}\right]^{-\frac{1}{\kappa}}
$$

\subsection{Consumers Optimization Problem}

Each consumer will solve a standard optimization problem by maximizing utility with respect to a budget constraint. The instantaneous utility index for individual $i$ is given by

$$
U\left(C_{i t}, L_{i t}\right)=\left[\log C_{i t}-\frac{\kappa}{\epsilon}\left(L_{i t}\right)^{\epsilon}\right]
$$

where

$$
L_{i t}=\left[\psi^{\frac{1}{v}}\left(L_{i t}^{H}\right)^{\frac{v-1}{v}}+(1-\psi)^{\frac{1}{v}}\left(L_{i t}^{N}\right)^{\frac{v-1}{v}}\right]^{\frac{v}{v-1}}
$$

Individuals derive utility from consuming goods and disutility from supplying labor to both sectors of domestic production. $\kappa$ is a scale parameter. In an intertemporal framework, and assuming a discount factor $\beta$, individuals solve ${ }^{10}$

$$
\max _{\left\{C_{i t}, L_{i t}\right\}} E_{t}\left\{\sum_{j=0}^{\infty} \beta^{j}\left[\log C_{i, t+j}-\frac{\kappa}{\epsilon} L_{i, t+j}^{\epsilon}\right]\right\}
$$

given (8), (9), and subject to a flow budget constraint

$$
W_{i t}^{N} L_{i t}^{N}+W_{i t}^{H} L_{i t}^{H}=P_{t}^{N} C_{i t}^{N}+P_{t}^{H} C_{i t}^{H}+S_{t} C_{i t}^{F}+S_{t} B_{t}^{*}-S_{t} B_{t-1}^{*}(1+\iota)
$$

in which consumption is made out of the income received by working in either sector of the domestic economy. $B_{t}^{*}$ represents international assets hold by consumers, the latter paying an interest rate equal to $\iota$.

First order conditions for individual $i$ are as follows:

$$
\begin{gathered}
\frac{C_{i t}^{T}}{C_{i t}^{N}}=\frac{\gamma}{1-\gamma}\left(\frac{P_{t}^{T}}{P_{t}^{N}}\right)^{-\rho} \\
\frac{C_{i t}^{F}}{C_{i t}^{H}}=\frac{1-\phi}{\phi}\left(\frac{P_{t}^{F}}{P_{t}^{H}}\right)^{-\varsigma} \\
\frac{1}{C_{i t}} \frac{W_{i t}^{N}}{P_{t}}=\kappa \psi^{\frac{1}{v}}\left(L_{i t}^{N}\right)^{-\frac{1}{v}} L_{i t}^{\epsilon-1+\frac{1}{v}} \\
\frac{1}{C_{i t}} \frac{W_{i t}^{H}}{P_{t}}=\kappa(1-\psi)^{\frac{1}{v}}\left(L_{i t}^{H}\right)^{-\frac{1}{v}} L_{i t}^{\epsilon-1+\frac{1}{v}}
\end{gathered}
$$

\footnotetext{
${ }^{10}$ The uncertainty refers to the international price of home goods, which is exogenous and, in terms of the experiment below, will represent the shock to terms of trade, given that we have assumed that $P_{t}^{F *}=1 \forall t$.
} 


$$
E_{t}\left[\frac{C_{t}}{C_{t+1}} \beta(1+\iota) \frac{P_{t}}{P_{t+1}}\right]=1
$$

The intuition of these FOC's is straightforward. (19) shows that the relative demand for tradables to non-tradables depends negatively on relative prices. (20) implies that the relative demand for foreign goods to home goods is also negatively related to relative prices. (21) and (22) display the labor supply functions in the non-tradable and home goods sectors, respectively, both increasing in the real wage paid in each sector.

\subsection{Entrepreneurs}

Entrepreneurs in sector $J$ consume $\left(1-\delta^{J}\right)$ of their net cash flow, which for tractability is assumed to be entirely spent on imports. In each period, the share of the cash flow that is not consumed is re-invested in purchasing the capital that firms use to produce. We assume that the value of their net worth - cash flow - in period $t$ is not enough to purchase capital, driving them to borrow in international credit markets.

The domestic currency value of the capital purchased during period $t$ (that will produce during period $t+1$ ) equals $Q_{t}^{J} K_{t}^{J}$, where $Q_{t}^{J}$ is the price of capital in sector $J$ during period $t$. This will be financed by (the domestic value of) net worth in period $t$ for sector $J, P_{t}^{J} N_{t}^{J}$, and by borrowing in international financial markets an amount $B_{t}^{J}$ in foreign currency, thus implying that the domestic currency value of that debt will be priced at the nominal exchange rate, $S_{t}$ :

$$
Q_{t}^{J} K_{t}^{J}=P_{t}^{J} N_{t}^{J}+S_{t} B_{t}^{J}
$$

We assume entrepreneurs to be risk neutral. Therefore, they will demand capital and borrow funds according to the expected rate of return on capital, measured in terms of foreign currency. The latter will be the ratio between the value of the expected return obtained from capital in period $t+1$ (this comes from (5)) to the original cost of purchasing that capital during period $t$, both valued in real terms, thus deflated by the exchange rate. Namely,

$$
\frac{E_{t}\left[\frac{\alpha^{J} P_{t+1}^{J} Y_{t+1}^{J}}{S_{t+1}}\right]}{\frac{Q_{t}^{J} K_{t}^{J}}{S_{t}}}
$$

where we have assumed a depreciation rate of $100 \%$.

However, risk neutral international financial markets perceive the existence of some default risk on private lending. Given that depending on the state of nature some loans will become nonperforming, lenders optimally choose the debt contract so as to account for the latter. Bernanke, Gertler and Gilchrist (2000) and Céspedes (2000) show that the construction of the contract is a standard debt contract in the presence of idiosyncratic and aggregate risk, in which domestic entrepreneurs are charged a risk premium on their borrowing contracts - this is done for a onegood economy as well as for a two-good economy that involves a relative price. We follow them in 
this respect. 11

In equilibrium, the expected real rate of return to capital should equal the cost of borrowing, the latter being the composite of the gross riskless international interest rate scheduled in period $t, \iota_{t}$, and the gross risk premium paid in period $t$ by sector $J, \eta_{t}^{J}$.

$$
\frac{E_{t}\left[\frac{\alpha^{J} P_{t+1}^{J} Y_{t+1}^{J}}{S_{t+1}}\right]}{\frac{Q_{t}^{J} K_{t}^{J}}{S_{t}}}=\iota_{t} \eta_{t}^{J}
$$

Furthermore, the external finance premium paid by entrepreneurs is endogenous and depends on the ratio of total dollar debt to net worth in an increasing manner. The higher the ratio of debt to net worth - to be defined shortly -, the higher the risk premium will be, given increased chances of entrepreneurs going bankrupt and therefore not being able to repay their debts ${ }^{12}$

$$
\eta_{t}^{J}=F\left(\frac{\frac{S_{t} B_{t}^{J}}{P_{t}^{J}}}{N_{t}^{J}}\right)=f\left(\frac{Q_{t}^{J} K_{t}^{J}}{P_{t}^{J} N_{t}^{J}}\right)
$$

with $F^{\prime}>0, f^{\prime}>0, F(1)=1, f(1)=1, F(\infty)=\infty, f(\infty)=\infty$.

Moreover, it is straightforward to notice that this essentially implies a risk premium that is increasing in the leverage of the entrepreneur. ${ }^{13}$

Entrepreneurs in sector $J$ are assumed to consume $\left(1-\delta^{J}\right)$ of their income and then devote the rest of it to purchase capital, as stated above. This implies that each period, net worth will consist of the non-consumed returns to capital invested in production, net of debt repayment, i.e.,

$$
P_{t}^{J} N_{t}^{J}=\delta^{J}\left[R_{t}^{J} Q_{t-1}^{J} K_{t-1}^{J}-\iota_{t-1} \eta_{t-1}^{J} S_{t} B_{t-1}^{J}\right]
$$

This gives, after considering (5),

$$
N_{t}^{J}=\delta^{J}\left[Q_{t-1}^{J} \alpha^{J} Y_{t}^{J}-\iota_{t-1} \eta_{t-1}^{J} \frac{S_{t}}{P_{t}^{J}} B_{t-1}^{J}\right]
$$

This implies that net worth in sector $J$ during period $t$ increases with output, the price of capital and prices and decreases with the exchange rate, the international riskless interest rate and the risk premium. Notice also the following intertemporal link. The external finance premium paid in period $t$ is the one set during period $t-1$, which at the same time endogenously depends on the net worth level of period $t-1$. This generates the seeds for a shock-propagation mechanism, because negative shocks during $t-1$ will reduce entrepreneur's net worth, thus curtailing their ability to purchase capital for period $t$. In turn, this is reflected in a higher risk premium which

\footnotetext{
${ }^{11}$ Here we are not dealing with the problem of why international lenders extend loans to non-tradable producers, considering that their sales are exclusively in domestic currency, unlike producers of tradables that can export, which might seem a suboptimal behavior from the point of view of lenders. For related literature on this issue see Caballero and Krishnamurthy (2001) and Jeanne (2001).

${ }^{12}$ See Bernanke, Gertler and Gilchrist (2000) for details.

${ }^{13}$ This comes as a result of incorporating (24) into (27).
} 
endogenously reduces net worth for period $t$, thus propagating the effects of the shock to subsequent periods. Similarly, this can arise as a consequence of variations in international riskless interest rates, unexpected changes in real return to capital or unanticipated real devaluations; this point is picked up below.

\subsection{Capital Producers}

There is a sector devoted to the production of capital that is sector-specific, in a standard fashion. Specifically, capital producers in sector $J$ purchase output in sector $J$ at the end of period $t$ and use it to produce capital that will used by entrepreneurs in sector $J$ to produce during period $t+1$. In order to do so, we assume that they have a concave production function which reflects the existence of convex capital adjustments costs; for simplicity, we also assume a depreciation rate of $100 \%$. Therefore, the production function looks as follows

$$
K_{t}^{J}=\Phi\left(\frac{K_{t}^{J}}{K_{t-1}^{J}}\right) K_{t-1}^{J}
$$

with $\Phi^{\prime}>0$ and $\Phi^{\prime \prime}<0$. This implies that the price of capital - consistent with the standard Q-theory of investment - will be given by

$$
\frac{Q_{t}^{J}}{P_{t}^{J}}-\left[\Phi^{\prime}\left(\frac{K_{t}^{J}}{K_{t-1}^{J}}\right)\right]^{-1}=0
$$

\subsection{Resource Constraints}

Goods produced in the non-tradables sector will be either consumed by workers or by capital producers

$$
Y_{t}^{N}=C_{t}^{N}+K_{t}^{N}
$$

and goods domestically produced in the tradable sector will be either consumed by workers, capital producers or the rest of the world

$$
Y_{t}^{H}=C_{t}^{H}+K_{t}^{H}+X_{t}
$$

where $X_{t}$ denotes exports. ${ }^{14}$

As in Gali and Monacelli (2002), we impose that the trade balance should be in equilibrium in steady state. Since the unit mass of consumers are all alike, the bonds market should clear for an aggregate net supply equal to zero, as in Faia (2003):

\footnotetext{
${ }^{14}$ Note that as far as the domestic economy is sufficiently small, in the sense that rest of the world's expenditure share in this country' s goods is small enough cum a unitary elasticity of substitution, the foreign currency value of exports can be taken as given, as in Céspedes, Chang and Velasco (2001a, 2001b and 2001c) and Krugman (1999). Alternatively, we could have considered some demand for exports of the form $X_{t}={\frac{P_{t}^{H *}}{P_{t}^{F *}}}^{-\tau} Y_{t}^{*}$, for $Y_{t}^{*}$ given.
} 


$$
B_{t}^{*}=0
$$

\subsection{Equilibrium}

For the purpose of this model, we define a fixed exchange rate policy as the one that keeps the nominal exchange rate constant, i.e $S_{t}=S_{t+i} \forall i$. We define a flexible exchange rate policy as that in which the nominal exchange rate makes all the adjustment to keep the nominal aggregate price from fluctuating, i.e. $P_{t}=P_{t+i} \forall i$, in line with $\mathrm{CCV}$. Note that this can be characterized as the limit of an inflation target scheme.

We define a rational expectations stochastic dynamic general equilibrium as the set of processes $\left\{C_{t}^{H}, C_{t}^{N}, L_{t}^{H}, L_{t}^{N}, W_{t}^{H}, W_{t}^{N}, P_{t}, P_{t}^{H}, P_{t}^{N}, K_{t}^{H}, K_{t}^{N}, Q_{t}^{H}, Q_{t}^{N}, \eta_{t}^{H}, \eta_{t}^{N}, N_{t}^{H}, N_{t}^{N}, Y_{t}^{H}, Y_{t}^{N}, B_{t}^{H}, B_{t}^{N}\right\}_{t=0}^{\infty}$ that maximize consumer's utility, firms' profits, entrepreneurs' rate of return and capital producer's profits given each sector's budget constraint and the aggregate economy's resource constraint, i.e. that satisfy (1), (2), (4)-(14), (18)-(24), (26)-(27), (29)-(33), along with an exchange rate policy rule - fixed or flexible, as defined above - and to the stochastic exogenous processes distributions for $P_{t}^{F *}, A_{t}^{H}, A_{t}^{N}, \iota_{t}$ and $X_{t}$ defined in the appendix.

Given the non-linear nature of the model above described, the solution is computed by approximating the dynamics of the model around the deterministic steady state and then observing the optimal response of the economy to different real shocks arising from the stochastic processes introduced in the previous paragraph, namely shocks to terms of trade, the international riskless interest rate, technology in each sector and export demand. ${ }^{15}$ In the exercise below we only report the results for shocks to the terms of trade. In the appendix we show the uniqueness of the steady state of the economy, which only depend on parameter values. Prior to presenting the results, the next section develops some theoretical underpinnings that are at the heart of explaining the results obtained in the impulse response below.

\section{Nonlinear Effects of Unanticipated Real Price Changes}

As described in the introduction, there are some nonlinearities that arise when unanticipated changes in real prices occur. This gives rise to system dynamics in response to small real shocks, in which the credit market is the transmission mechanism for amplification and propagation. Specifically, this section analyzes the underlying mechanism in the economy's response to unanticipated changes in the real return to capital and unanticipated real devaluations. We find a strong nonlinearity in net worth and in the risk premium in response to the mentioned shocks: the elasticity of net worth with respect to these unanticipated changes in real prices is not constant, but increasing in the degree of leverage of the economy. Furthermore, given the intrinsic trap in which producers of non-tradables are involved - the lack of a "rest of the world" market to which they can re-channel

\footnotetext{
${ }^{15}$ Obviously, we are considering shocks that can be labelled as "small".
} 
their production when domestic demand is depressed - then the output composition, or degree of openness of the economy plays a crucial role in the selection of the optimal exchange rate regime.

In order to show this, we proceed as follows. Rewrite (29)

$$
N_{t}^{J}=\delta^{J}\left[\frac{Q_{t-1}^{J} R_{t}^{J} K_{t-1}^{J}}{P_{t}^{J}}-\iota_{t-1} \eta_{t-1}^{J} \frac{S_{t} B_{t-1}^{J}}{P_{t}^{J}}\right]
$$

which by use of (24) results in

$$
N_{t}^{J}=\delta^{J}\left[\frac{Q_{t-1}^{J} R_{t}^{J} K_{t-1}^{J}}{P_{t}^{J}}-\iota_{t-1} \eta_{t-1}^{J} \frac{S_{t}}{S_{t-1} P_{t}^{J}}\left(Q_{t-1}^{J} K_{t-1}^{J}-P_{t-1}^{J} N_{t-1}^{J}\right)\right]
$$

Now take expectation on both sides of the latter expression given the information available as of period $t-1$. Subtracting it from the former, we obtain

$$
\begin{aligned}
& N_{t}^{J}-E_{t-1}\left(N_{t}^{J}\right)= \\
& \quad \delta^{J}\left\{\left[\frac{R_{t}^{J}}{P_{t}^{J}}-E_{t-1}\left(\frac{R_{t}^{J}}{P_{t}^{J}}\right)\right] Q_{t-1}^{J} K_{t-1}^{J}-\iota_{t-1} \eta_{t-1}^{J}\left(Q_{t-1}^{J} K_{t-1}^{J}-P_{t-1}^{J} N_{t-1}^{J}\right)\left[\frac{S_{t}}{S_{t-1} P_{t}^{J}}-E_{t-1}\left(\frac{S_{t}}{S_{t-1} P_{t}^{J}}\right)\right]\right\}
\end{aligned}
$$

Let

$$
U^{\Delta R^{J}}=\frac{R_{t}^{J}}{P_{t}^{J}}-E_{t-1}\left(\frac{R_{t}^{J}}{P_{t}^{J}}\right)
$$

and

$$
U^{\Delta S^{J}}=\frac{S_{t}}{S_{t-1} P_{t}^{J}}-E_{t-1}\left(\frac{S_{t}}{S_{t-1} P_{t}^{J}}\right)
$$

be the unanticipated change in the real return to capital in sector $J$ during period $t, U^{\Delta R^{J}}$, and the unanticipated devaluation effect on sector $J, U^{\Delta S^{J}}$, respectively.

Therefore, introducing (37) and (38) we get

$$
N_{t}^{J}=\delta^{J}\left[U^{\Delta R^{J}} Q_{t-1}^{J} K_{t-1}^{J}-\iota_{t-1} \eta_{t-1}^{J}\left(Q_{t-1}^{J} K_{t-1}^{J}-P_{t-1}^{J} N_{t-1}^{J}\right) U^{\Delta S^{J}}\right]+E_{t-1}\left(N_{t}^{J}\right)
$$

Computing the elasticity of net worth with respect to unanticipated changes in the real return to capital, we obtain:

$$
\frac{\partial N_{t}^{J} / E_{t-1}\left(N_{t}^{J}\right)}{\partial U^{\Delta R^{J}} / E_{t-1}\left(\frac{R_{t}^{J}}{P_{t}^{J}}\right)}=\frac{\delta^{J} Q_{t-1}^{J} K_{t-1}^{J} E_{t-1}\left(R_{t}^{J} / P_{t}^{J}\right)}{E_{t-1}\left(N_{t}^{J}\right)} \geq 1
$$

where the inequality in (40) is implied by taking expectations as of $t-1$ of both sides by (37). From (40) we observe that the elasticity of net worth with respect to unanticipated changes in the 
real return to capital is greater than one. ${ }^{16}$

Notice that the size of the elasticity is not constant, but depends on the degree of leverage, which is essentially the domestic value of foreign debt. This can be seen by rearranging (37) as follows:

$$
N_{t}^{J}+\delta^{J} \iota_{t-1} \eta_{t-1}^{J} \frac{S_{t}}{S_{t-1} P_{t}^{J}}\left(Q_{t-1}^{J} K_{t-1}^{J}-P_{t-1}^{J} N_{t-1}^{J}\right)=\delta^{J} \frac{R_{t}^{J}}{P_{t}^{J}} Q_{t-1}^{J} K_{t-1}^{J}
$$

If the real return to capital decreases unexpectedly, the value of net worth drops, generating a lower demand for investment. This, in turn, decreases its price, consequently increasing the risk premium, which reduces net worth further down, therefore increasing the risk premium, etc., so on and so forth. As a result, unexpected changes in real return to capital generates a more than proportional fall in output, through some type of multiplier process. Notice the similarity of this result with the debt-deflation theory of business cycles due to Irving Fisher (1933) ${ }^{17}$ in that unanticipated drops in real prices are the amplification and transmission mechanism for business cycles fluctuations.

By computing the elasticity of net worth with respect to unexpected devaluations from (39), it is straightforward to show that

$$
\frac{\partial N_{t}^{J} / E_{t-1}\left(N_{t}^{J}\right)}{\partial U^{\Delta S^{J}} / E_{t-1}\left(\frac{S_{t}}{S_{t-1} P_{t}^{J}}\right)}=-\frac{\delta^{J} \iota_{t-1} \eta_{t-1}^{J}\left(Q_{t-1}^{J} K_{t-1}^{J}-P_{t-1}^{J} N_{t-1}^{J}\right) E_{t-1}\left(\frac{S_{t}}{S_{t-1} P_{t}^{J}}\right)}{E_{t-1}\left(N_{t}^{J}\right)}
$$

This suggests that whenever unanticipated devaluations occur, net worth decreases; furthermore, for high degrees of leverage - i.e. for high levels of the domestic value of foreign debt - this elasticity is likely to be greater than one in absolute value. In the latter case, the above mentioned nonlinearity appears: real devaluations' effects are increasing in the degree of leverage. Since in the short run the capital stock is fixed (given from the previous period), then any change in a relative price affects net worth. Furthermore, it is straightforward to show that since the elasticity of the real value of debt with respect to unanticipated changes in the real exchange rate equals one, then the nonlinearity is directly transmitted to the external finance premium: this premium is not only an increasing function of the degree of leverage, but it is also affected in a nonlinear way by unexpected changes in unanticipated real devaluations, the impact being greater the higher the degree of leverage. ${ }^{18}$ For firms that have a market where they can redirect their sales after the devaluation, it might be worth paying the extra risk premium - see (26) - but this will not be true for non-tradables.

For economies that are highly leveraged - i.e. highly indebted in foreign currency - unanticipated devaluations cause net worth and therefore the external finance premium to increase more

\footnotetext{
${ }^{16}$ For $\delta^{J} \rightarrow 1$, as will be the case in the calibrated economy below.

${ }^{17}$ This is similar in spirit to Kiyotaki and Moore (1997) and BGG (1999).

${ }^{18}$ The elasticity of risk premium with respect to unanticipated devaluations is also increasing in the degree of leverage.
} 
than proportionally. This reduces demand for investment and consequently the price of net worth, thus raising the external finance premium further, again though a multiplier process, which eventually is reflected in output as well. In a sense, this works like a debt-deflation (Fisher) effect for open economies. The magnitude of the effect depends on the degree of dollarization of debts cum the degree of openness of the economy - i.e. on the degree of currency mismatch. For relatively closed economies, this transmission and propagation mechanism effects for shocks gets enlarged because of the greater impact it generates on producers of non-tradables. This is due to the lack of an alternative market where they can re-direct their production, which in turn further affects the risk premium. As a consequence, this anticipates a differentiated role for the exchange rate arrangement depending on the output composition of the economy. And this is due to the unequal effect of this mechanism on different sectors, as will be shown below.

Another way to put it is that there is a magnification effect though which unexpected movements in real prices have a substantial effect on the financial position of entrepreneurs. As will become clear below, this will explain an important part of the dynamics of the model in the impulse response analysis. Furthermore, it sets some ground for the discussion short-sharp vs. long-mild suggested in the introduction.

\section{$5 \quad$ Impulse Response Analysis}

In this section we study the effects of negative terms of trade shocks. The dynamics of the model are analyzed by observing the evolution of the variables around the steady state when hit by a "small" shock. In order to do so, and given the fundamental non-linearity of the model, we first log-linearize it around the steady state. The Appendix describes the complete log-linearization of the system in detail, as well as the parametrization of the steady state. It also shows the uniqueness of the latter.

For the purpose of the experiment, we assume that the economy is in steady state and is suddenly affected by a $10 \%$ decrease in the international price of home goods, $P_{t}^{H *}$; recall that we have assumed that the international price of foreign goods is constant an equal to one in steady state as well as off the steady state. The size of the shock is not arbitrary, but taken form the documented evidence: Magud (2003b) analyzed the standard deviation of the residuals. This implied a shock of size in the range of $5 \%$ to $15 \%$. In calibrating the model, the intention is to replicate the empirical evidence as close as possible. This is obtained by assuming a shock of $10 \%$ (negative decrease in the terms of trade). Also, the residuals show a persistence of 0.45 . This is also included in the simulations below. Note that the latter value is consistent with Mendoza (1995), who finds an autocorrelation coefficient of 0.41 . The discount rate equals 0.9615 . As a result, each period in the impulse-response below corresponds to a year, assuming an annual interest rate of $4 \%$. Once more, this is to make the theoretical model comparable with the evidence below.

The exercise is done for what we label "relatively open economies" and for "relatively closed economies" within the set of small open economies. In this respect, the first subsection analyzes 
the impulse-response of a an economy with a share of $70 \%$ of tradables in domestic production. In the second subsection we change the share of tradables to $30 \%$. The choice of the degree of openness is not arbitrary. As shown in t Magud (2003b), these values emerge from observing the data for a 32 country sample covering the period 1980-2001. In the latter, relatively open economies average a $70 \%$ of openness, while relatively closed economies average $30 \%$. We will observe marked differences.

It is worth noting that similar results are obtained for a variety of different real shocks such as shocks to the international (riskless) interest rate, productivity shocks, as well as export demand shocks. The case of interest rate shocks could be considered the most of important of these. Small open economies are frequently affected by fluctuations in this interest rate as a result of counter-cyclical monetary policies in large countries. Also, contagion can be characterized in terms of interest rate volatility. Thus, analyzing these shocks in the context of the model is a natural extension. Intuitively, increases in the world interest rate raise the rate paid on foreign currency loans, thus generating similar effects as real devaluations - supply contractions - as will be shown below. Also, increasing the opportunity cost of consumption increases savings, thus reducing domestic demand. In summary, as will clear from the analysis of the impulse response, shocks to terms of trade are similar in nature to real devaluations. For lack of space results are not reported here.

\subsection{Relatively Open Economies}

As Figure 2 illustrates for the case in which the tradable to GDP ratio equals 0.7, when a relatively open economy is hit by a terms of trade shock, output falls independently of whether the exchange rate regime is flexible or fixed. Note the consistency with conventional wisdom in that flexible exchange rates perform better as a real shock absorber. We observe that if the country operates under a float the output drop on impact is smaller than if the country's regime is a pure fix, as the previous literature claims. Depending on parameter values, we observe at most one time period during which output under a flexible regime is below output under a fixed regime.

In Figures 3 and 4 we observe the temporal trajectory of several variables. As a result of the shock, aggregate demand for consumption goods decreases. Moreover, given the change in relative prices, the relative demand for non-tradables increases: the demand for non-tradables does not decrease as much as demand for home goods regardless of the exchange rate regime.

With flexible exchange rates - Figure 3 - the nominal devaluation that accommodates the negative terms of trade shock drives the price of home goods up, reflecting the pass-through of exchange rate fluctuations. Since demand for non-tradables decreases, so does its price to clear the domestic market. This explains the real exchange rate depreciation observed in Figure 5. Output drops in both sectors, as well as labor. Notice that risk premium increase in both sectors. However, it increases substantially more in the non-tradable sector. In turn, this is reflected in net worth. The latter increases on impact for the home goods, while it decreases for the non-tradable 


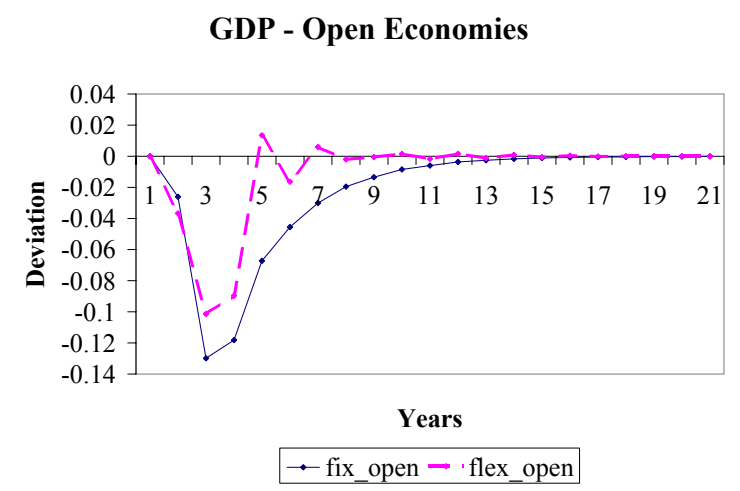

Figure 2: Output dynamics with flexible and fixed exchange rate regimes for relatively open economies.
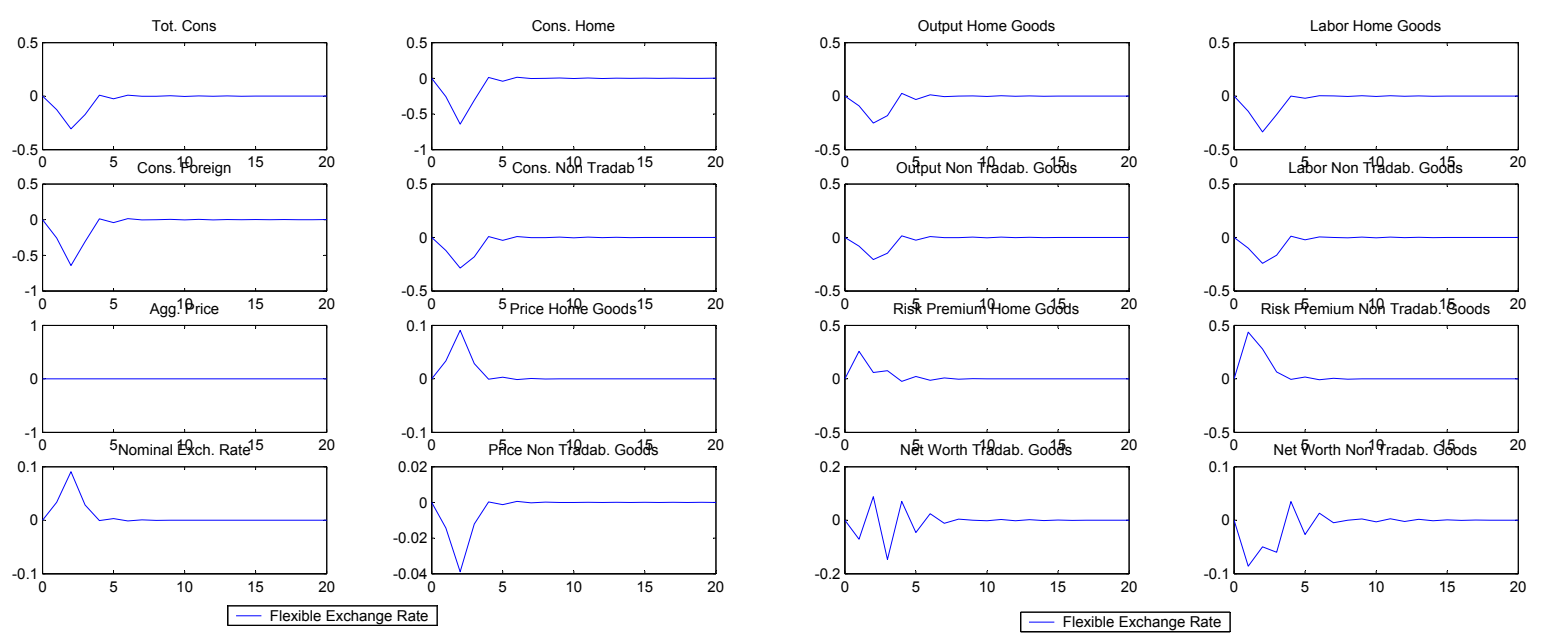

Figure 3: Consumption, prices, output, labor, external finance premium and net worth dynamics with flexible exchange rate regimes for relatively open economies.

sector. This results from the combined effect of the price fluctuation above described, as well as the increase in the real value of debt triggered by the real devaluation.

If the economy is under a fixed exchange rate regime, similar patterns are observed regarding aggregate consumption. This can be seen in Figure 4. Also, the relative demand for non-tradables increases: demand for non-tradables drops less than demand for home goods. Again, this results from the relative price change: prices for home goods are almost constant, while the price for non-tradables decreases. Notice in Figure 5 that the real exchange rate depreciation under a fixed exchange rate is smaller than when the economy is ruled by a flexible regime. It can be seen that the risk premium increases proportionally more in the non-tradable sector, compared with the home goods sector. Once more, this is reflected in the net worth plot.

In summary, output is reduced in both sectors of the economy, regardless of the exchange rate 

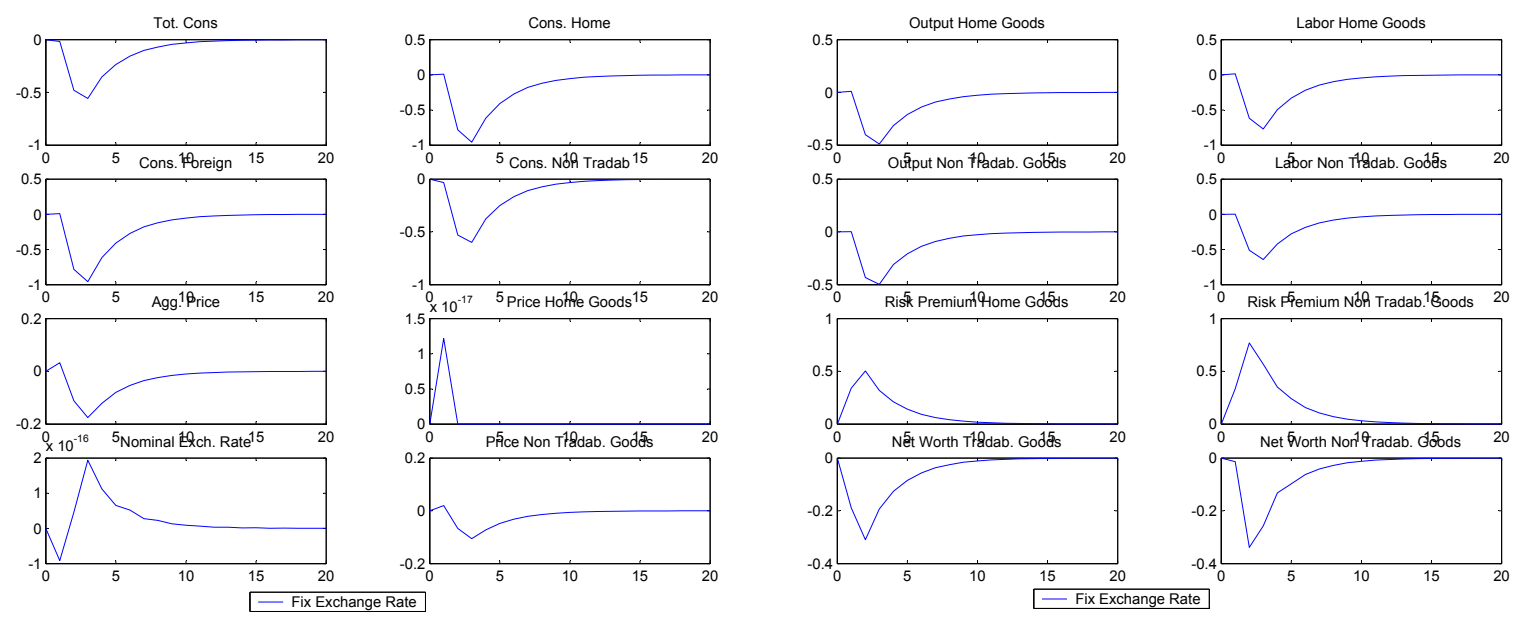

Figure 4: Consumption, output, labor, external finance premium and net worth and prices dynamics with fix exchange rate regimes for relatively open economies.

regime. However, the aggregate output drop is deeper if the economy's exchange rate regime is fixed. The intuition for this is as follows. In the presence of a flexible regime, the negative shock triggers a real depreciation that decreases domestic demand, thus reducing firms' sales in domestic markets. Furthermore, the depreciation increases the foreign currency repayment of the debt for entrepreneurs in both the home and non-tradable sectors, thus reducing net worth. In turn, this curtails the ability to purchase capital to produce the following period because of the increased risk premium. ${ }^{19}$ For tradables, however, the real depreciation implies an increase in competitiveness, enabling them to re-direct their output towards the rest of the world, unlike producers of nontradables. The former, although with reductions in quantities, experience a relative price increase, compared to non-tradables, which impacts the value of output. Therefore, producers of tradables are not affected as much as producers of non-tradables are. Furthermore, individuals anticipate an increase in demand for home goods, thus making the external finance premium not increase as much. This allows entrepreneurs in this sector to purchase additional capital, as it is observable from (25). Since most of the output generated in the economy is tradable, flexible exchange rate are preferred. If instead the economy were to be under a fixed regime, the expansionary effects for the tradable sector coming from competitiveness would not exist. In this case, although tradables and non-tradables producers will be less affected by the increase in the burden of their dollar liabilities, tradables producers will still be worse on balance. As long as there is a high share of domestic output that is tradable, fixed regimes will benefit only a small fraction of the economy. This explains why we observe that for a relatively open economy the output drop is deeper with a

\footnotetext{
${ }^{19}$ Recall that the risk premium is endogenous and nonlinearly increasing in the entrepreneur's leverage. Thus, an increase in real - in foreign currency units - debt accompanied by a decrease in net worth implies a reduced ability to repay debts (i.e. a higher leverage), thus triggering an increase in the risk premium.
} 
fixed exchange rate than when the economy lives under a flexible regime. This is also reflected in the external finance premium. By inspection of Figures 3 and 4, notice that the external finance premium increases less for the home goods sector under flexible exchange rates. It also increases more for non-tradables, but this is due to the economy being relatively open. Also, net worth in the tradable sector increases with flexible exchange rates. This results from the competitiveness effect: although the external finance premium increases, it is worth paying it.

As the reader might have already noticed, the above results are in line with conventional wisdom, even though balance sheet effects are included. These results are qualitatively similar to Céspedes, Chang and Velasco (2001) and Gertler, Gilchrist and Natalucci (2001). The specific reason for this is that the ratio of tradables to GDP is sufficiently high and that the aforementioned papers deal with economies in which all goods are tradable. Thus, although this model is somewhat different, it can replicate existing results.

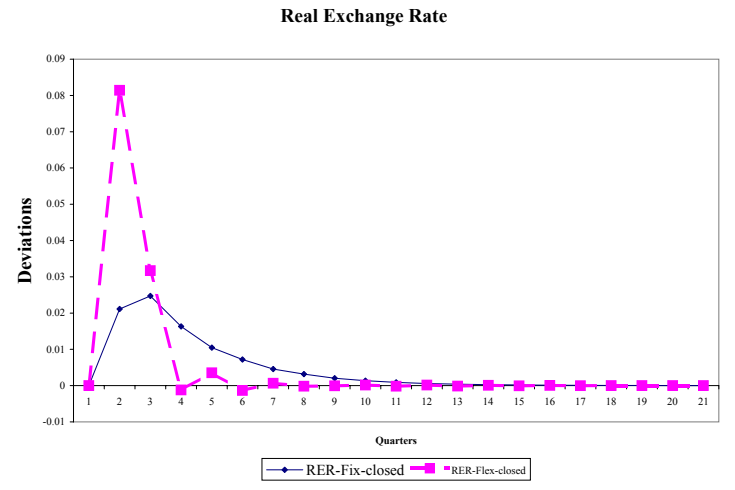

Figure 5: Real Exchange Rate dynamics with flexible and fixed exchange rate regimes for relatively open economies.

\subsection{Relatively Closed Economies}

Let us now repeat the exercise with only one minor modification: the ratio of tradables to GDP now equals 0.3 , representing a relatively closed economy. ${ }^{20}$

In this case, we observe in Figure 6 that the economy's response to the same terms of trade shock is larger on impact when the economy is ruled by a flexible exchange rate regime, unlike the previous case. Furthermore, there is higher volatility under the latter regime, suggesting a welfare reduction.

As shown in Section (4), the explanation for this pattern comes from the endogenous effects of unanticipated changes in real prices: when there is a fixed regime, although firms in the home goods cannot use the instantaneous realignment of relative prices to re-channel the domestic demand drop to the rest of the world, non-tradables do not observe an increase in the value of debt. This implies

\footnotetext{
${ }^{20}$ See the Appendix for the complete set of parameter values.
} 


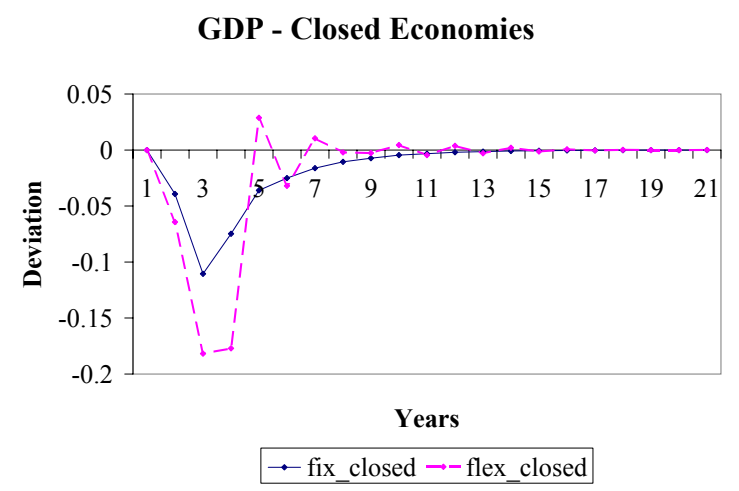

Figure 6: Output dynamics with flexible and fixed exchange rate regimes for relatively closed economies.
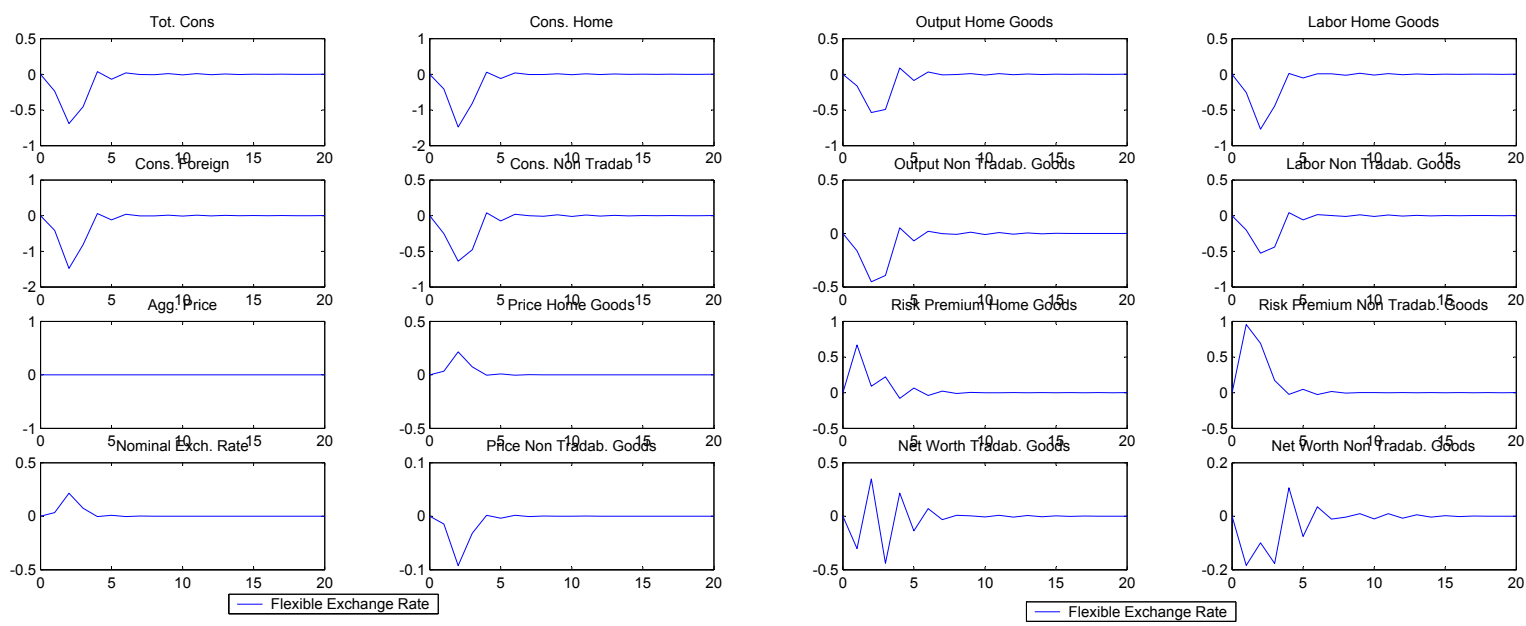

Figure 7: Consumption, output, labor, external finance premium, net worth and prices dynamics with flexible exchange rate regimes for relatively closed economies.

that the external finance premium does not increase as much (for both sectors, but having a higher incidence for non-tradables) and therefore permits them to manage the shock more easily.

As before, we can see in Figure 8 that domestic demand for consumption goods decreases, but demand for non-tradables does not decrease as much, due to the change in relative prices. This occurs regardless of the exchange rate regime. Also, we notice the pass-though effect that occurs with flexible exchange rates: home goods prices increase. At the same time, non-tradables prices decrease to clear a depress domestic market, as in the relatively open economy. Again, this implies the real exchange rate depreciation pictured in Figure 5 above. In line with the relatively open economy, when the economy is under a fixed regime, since the price for home goods as well as the nominal exchange rate do not change much while the price of non-tradables drops, the real exchange rate depreciates. However, the real depreciation is smaller on impact if the economy is 

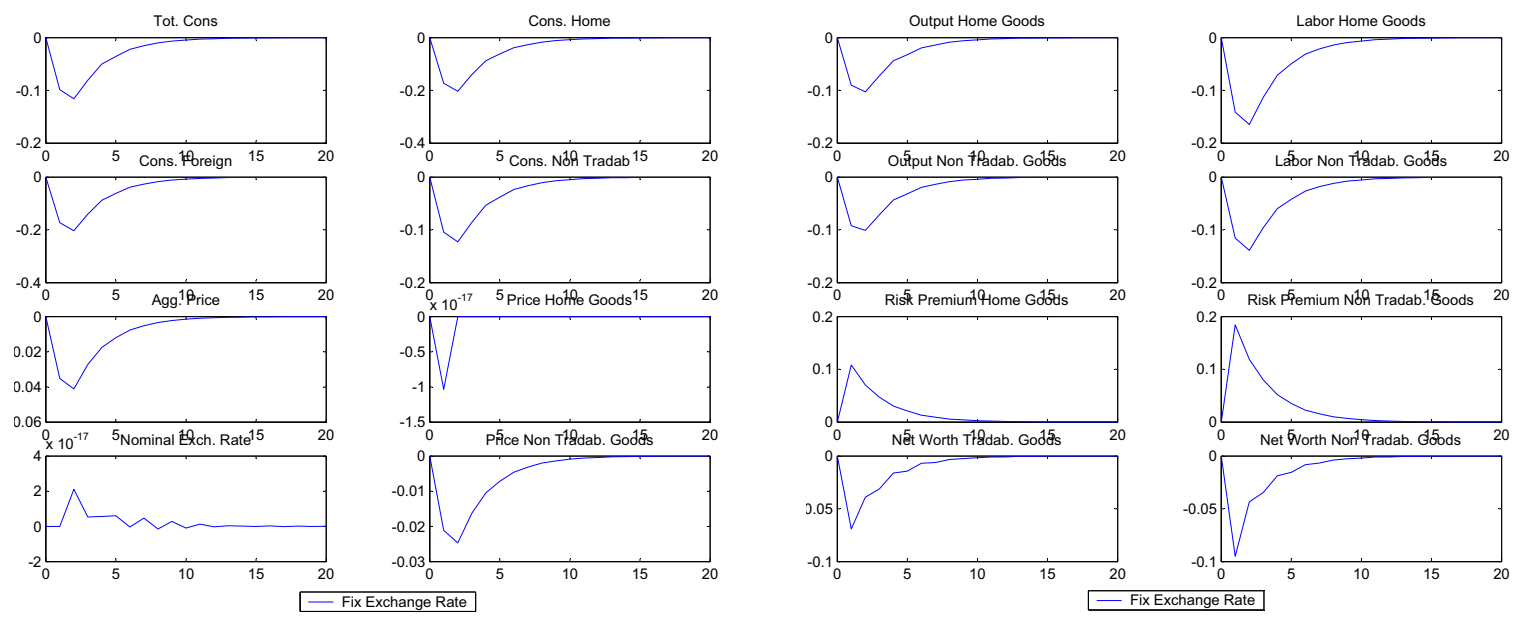

Figure 8: Consumption, output, labor, external finance premium, net worth and prices dynamics with fixed exchange rate regimes for relatively closed economies.

ruled by a fixed exchange rate.

As in the previous section, output and labor drop in both sectors in response to the negative terms of trade shock. The external finance premium increases in both sectors, due to the decline in net worth, as expected.

In summary, we observe that for a relatively closed economy, a fixed exchange rate regime seems to outperform a flexible regime, contrary to our previous findings. The section below analyzes the origins of these differences.

\subsection{Policy Implications: "Short-Sharp vs. Long-Mild" - a Discussion}

The above discussion (in line with conventional wisdom) might suggest the benefits of bearing the whole burden of relative price adjustment at one point in time - the Short-Sharp case - instead of over a longer period - the Long-Mild case. That will be the case if the structure of the external finance premium is not taken into consideration. As shown in section (4), as long as the percentage increase in external finance premium is nonlinear in the entrepreneur's leverage, the effects of unanticipated real devaluations depend on the initial degree of leverage. Specifically, unanticipated drops in real returns to capital and/or real depreciations generate a more than proportional decrease in net worth. In turn, that will imply a more than proportional increase in the external finance premium, thus reducing the ability of firms to invest. Consequently, the lack of sufficient net worth becomes more "binding" a constraint to finance capital investments. The higher is the external finance premium elasticity with respect to unanticipated changes in real return to capital or unanticipated real devaluation is, the larger this effect on financing the purchase of capital is.

This gives rise a role for progressive relative price adjustments, because they enable entrepreneurs to cope with the shock without going bankrupt. Specifically, this suggests that a "Short- 
Sharp" recession may be more harmful than a "Long-Mild" recession. The intuition is the following. With relative prices progressively adjusting, the effect on the external finance premium (through the decrease in net worth that the real depreciation generates via the increase in the foreign-currency value of the entrepreneur's debt) is not as marked as when the exchange rate adjustments instantaneously. As a result, investment, although it drops, does not drop as sharply with a fixed exchange rate as with a flexible regime. Consequently, the output contraction is smoothed out. In other words, the fixed regime allows forward looking firms and lenders to accommodate a real shock without an output effect as large as with a flexible regime.

Furthermore, with a flexible exchange rate, shocks cause entrepreneur's net worth to become suddenly 'more binding'. This is due to the high elasticity of net worth with respect to unanticipated changes in relative prices. Since the higher the leverage, the greater this elasticity is, the larger the jump in the external finance premium will be following real price changes. In turn, this triggers a contraction in the non-tradable sector. Specifically, many entrepreneurs in this sector will go bankrupt due to the lack of time to accommodate the price change without large drops in investment. Notice that for tradables, the effect of the real exchange rate is smaller because of the expanded foreign demand that is observed after the devaluation - i.e the higher competitiveness that results from the devaluation.

All the above is also related to the intertemporal link described in Kiyotaki-Moore (1997). As a consequence of the shock, entrepreneurs reduce their current purchase of capital. This reduces their own revenue and consequently the future value of net worth. Furthermore, the reduction in prices makes the drop in the value of net worth larger. This curtails their ability to purchase capital in the next period. As a consequence of this, next period's net worth goes further down, further raising the external finance premium. In other words, this process - product of the shock - reduces capital purchases and consequently net worth, in a sort of "dynamic multiplier" effect.

A related issue is to define a relatively open as opposed to a relatively closed economy. Experiments suggest that in my model the threshold share of tradables below which a fixed regime outperforms a flexible regime is around $60 \%$. However, one should not regard this threshold as a precise policy recommendation, since this calibration may not be valid for a particular country in question.

It should be pointed out that these results where checked for robustness. Specifically, the same exercises were re-run several times, changing each of the parameters one at a time. This was done not only for the parameters values reported in the literature, but also for several "unrealistic" values, so as to verify if at least there could be a theoretically possible different result. However, the only differences that were observed were of quantitative, but not qualitative nature. For the reader's reference, the range of some parameters considered were: the elasticity of substitution among domestic goods between 10 and 0.5, the ratio of home goods in tradables from 0.1 to 0.97 , the elasticity of risk premium in the range 1 to 4 , leverage for each sector between 1.1 and 3.8, and $\alpha$ for each sector in the 0.15 - 0.5 range. Also, we tested labor income shares quite different from those empirically observed, as in Mendoza (2001), various discount factors in the interval 
0.95-0.9985, and others. ${ }^{21}$

It is worth mentioning, though, that the qualitative strength of the results do depend on the degree of persistence of the shock. Specifically, the more persistent the shock is, the higher the benefits of fixed exchange rates. For the higher the persistence, the lower the drop in output and the faster the recovery, especially under a fix exchange rate.

\section{Conclusions and Extensions}

The debate on the optimal exchange rate regime for emerging markets is far from closed. In the presence of nominal rigidities, the conventional wisdom for small open economies is that flexible exchange rates regimes improve the country's ability to cope with real shocks. This results from the advantage of a flexible nominal exchange rate that instantaneously accommodates changes in the real exchange rate without major real effects.

In the context of partial equilibrium models, some critics advocate fixed exchange rates as better real shock absorbers. Given foreign-currency denominated debt, real debt fluctuations can generate perverse real effects on the economy at business cycles frequencies. However, existing general equilibrium models incorporating balance sheet effects find that flexible exchange rates are still better at absorbing real shocks than fixed regimes.

This paper attempts to shed some light on one aspect of the analysis that has been apparently overlooked. The degree of openness of the economy plays a crucial role in determining the relative pros and cons in the adoption of an exchange rate regime for an emerging country. When an economy is highly open to world goods markets (i.e. if it produces a substantial amount of tradables as a percentage of GDP), the conventional wisdom still holds, notwithstanding the currency denomination of the country's debt. Introducing financial frictions enlarges the impact and propagation of the shocks, but does not overturn the qualitative advantage of flexible regimes in insulating the economy from real shocks.

However, for relatively closed economies, specifically those for which the component of nontradables in GDP is relatively high, the effects are the opposite. For a flexible regime, fluctuations in the exchange rate in response to negative terms of trade shocks imply increasing foreign-currencydenominated debts with decreasing domestic revenues. In response to a shock for which domestic demand decreases, producers of tradables have the ability to re-direct their output to the rest of the world. However, producers of non-tradables are restricted to a depressed domestic market. Furthermore, in the presence of financial frictions, this implies an increased external finance premium that is exacerbated for the non-tradable sector because its nature does not allow it to escape the currency mismatch.

Moreover, there is an intertemporal link similar in nature to Irving Fisher's (1933) debt-deflation theory. Entrepreneurs that currently observe a nonlinearly increased external finance premium

\footnotetext{
${ }^{21}$ It is worth mentioning that, for completeness, the exercise was also performed using the same elasticity of risk premium and degree of leverage for both sectors, without qualitatively different results.
} 
due to unanticipated devaluations or changes in the real return to capital are precluded from purchasing enough capital. This reduces their ability to produce next period, and consequently decreases their future net worth. In turn, this increases their future external finance premium. Since rational individuals anticipate this, the current period's external finance premium increased, and this generates an amplification of the current negative shock. Furthermore, the external finance premium increases nonlinearly in response to unanticipated changes in the real return to capital or unanticipated real devaluations.

As I argued before, the above mentioned effect impacts more on entrepreneurs that do not have a market where they can re-channel their output during a domestic recession, i.e. in non-tradables. As a result, the size of this sector in the economy ends up determining whether flexible exchange rates or fixed regimes should be preferred. Specifically, given foreign-currency-denominated debt, countries with a high degree of openness should prefer flexible regimes if they are mainly affected by real shocks. On the other hand, relatively closed economies will better absorb real shocks in fixed exchange rate regimes, contrary to conventional wisdom. ${ }^{22}$

There are some interesting extensions to this model. First, the government should be included. In the context of a flexible exchange rate regime for a relatively closed economy, and assuming that the government issues its own debt in foreign currency as the privates sector does, two effects arise: (i) if the economy is hit by a negative terms of trade shock that requires a jump in the exchange rate, the real burden of the public sector will automatically increase given its decreased ability to honor its foreign currency denominated obligations, while its tax revenues are denominated in domestic (and depreciated) currency decrease; this is a static effect; (ii) but there is a dynamic effect as well: the jump in the exchange rate is contractionary in terms of output, and thus reduces tax revenues. Then, by focusing on the intertemporal budget constraint of the government, it seem obvious that the derivative of the debt path increases: the devaluation does not only generate an increase in the government's stock of debt, but also in its growth rate; this will in turn increase the probability of default. ${ }^{23}$ Furthermore, if private sector's risk premium is attached to the government's risk premium - sort of country risk - the mentioned effect gets amplified.

Another extension focuses on the nominal rigidities of the model. Wages stickiness need not be the same under flexible and fixed exchange rate regimes. Specifically, the degree of wage indexation should be an optimal response to the exchange rate regime, instead of being the same in each regime. Endogeneizing the probability of wage setting according to the exchange rate regime would be a natural next step.

\footnotetext{
${ }^{22}$ This is also related to Mundell (1960) Optimal Currency Areas theory, in which a small open economy mainly affected by real shocks should adopt a fixed exchange rate regime.

${ }^{23}$ Which is increasing in the initial debt level. See Magud (2001).
} 


\section{References}

AGHiOn, P., BACHETTA, P. and BANERJEE, A. (2001). "Currency Crises and Monetary Policy in an Economy with Credit Constraints", European Economic Review, 45, (7), 11211150 .

ALESINA, A. and WAGNER, A. (2003). "Choosing (and Reneging on) Exchange Rate Regimes", National Bureau of Economic Research, Working Paper 9809, June.

BERNANKE, B. (1986). "Alternative Explanations of Money-Income Correlation", CarnegieRochester Conference Series on Public Policy, 25, 49-100.

BERNANKE, B. and GERTLER, M. (1989). "Agency Costs, Net Worth, and Business Fluctuations", American Economic Review, 73, June, 405-423.

BERNANKE, B., GERTLER, M. and GILCHRIST, S. (2000). "The Financial Accelerator in a Quantitative Business Cycle Framework", Handbook of Macroeconomics, Volume I, Taylor, J. and Woodford, M. (eds.), Elsevier Science, B.V., North Holland.

BRODA, C. (2000). "Terms of Trade and Exchange Rate Regimes in Developing Countries", mimeo, MIT.

CABAllero, R. and KRISHNAMURTHY, A. (2000) . "Excessive Dollar Debt: Financial Development and Underinsurance", Journal of Finance, forthcoming.

CALVO, G. (1999). "Fixed vs. Flexible Exchange Rates: Preliminaries of a Turn-of-Millennium Rematch", mimeo, University of Maryland at College Park.

CALVO, G. (1983). "Staggered Prices in a Utility-Maximizing Framework", Journal of Monetary Economics, 12, 383-98.

CALVO, G., IZQUIERDO, A., and TALVI, E. (2002). "Sudden Stops, the Real Exchange Rate and Fiscal Sustainability: Argentina's Lessons", mimeo, Inter-American Development Bank.

CALVO, G. and REINHART, C. (2002). "Fear of Floating", Quarterly Journal of Economics, 117, (2), 379-408.

CALVO, G. and REINHART, C. (2001). "Fixing for Your Life", Brookings Trade Forum 2000, S. Collins and D. Rodrik (eds.), Brookings Institution, Washington D.C.

CASHIN, P., CESPEDES, L. and SAHAY, R. (2002). "Keynes, Cocoa and Copper: in Search of Commodity Currencies", working paper, International Monetary Fund.

CAVAllo, M., KISSEleV, K., PERRI, F. and ROUBINI, N. (2002). "Exchange Rate Overshooting and the Costs of Floating", mimeo, New York University. 
CESPEDES, L. (2000). "Credit Constraints and Macroeconomic Instability in a Small Open Economy", mimeo, New York University.

CESPEDES, L., CHANG, R. and VELASCO, A. (2001a). "Balance Sheets and Exchange Rate Policy", mimeo, Harvard University.

CESPEDES, L., CHANG, R. and VELASCO, A. (2001b). "Balance Sheets, Exchange Rate Regimes, and Credible Monetary Policy", mimeo

CESPEDES, L., CHANG, R. and VELASCO, A. (2001c). "Dollarization of Liabilities, Net Worth Effects, and Optimal Monetary Policy", mimeo.

CHOI, W. and COOK, D. (2002). "Liability Dollarization and the Bank Balance Sheet Channel", mimeo, forthcoming in Journal of International Economics.

CHRISTIANO, L., GUST, C. and ROLDOS, J. (2002). "Monetary Policy in a Financial Crisis", mimeo, Northwestern University.

COOK, D. (2000). "Liability Dollarization and Stability: Monetary Policy and Foreign Currency Debt", mimeo, Department of Economics, Hong Kong University of Science and Technology.

DEVEREUX, M. (2001). "Financial Constraints and Exchange Rate Flexibility in Emerging Market Economies", mimeo, University of British Columbia.

DIXIT, A. and STIGLITZ, J. (1977). "Monopolistic Competition and Optimum Product Diversity", American Economic Review, 67, 297-308.

EDWARDS, S. and LEVY-YEYATI, E. (2002). "Flexible Exchange Rates as Shock Absorbers: an Empirical Investigation", mimeo.

FAIA, E. (2003. "Monetary Policy in a Currency Area with Imperfect Financial Integration and Financial Heterogeneity", mimeo, Univesitat Pompeu Fabra.

FISCHER, S. (2001). "Exchange Rate Regimes: Is the Bipolar View Correct?", Journal of Economic Perspectives, 15, (2), 3-24.

FISHER, I. (1933). "The Debt-Deflation Theory of Great Depressions", Econometrica, 1, October, $337-57$

FRIEDMAN, M. (1953). "The Case for Flexible Exchange Rates", in Essays in Positive Economics, University of Chicago, Chicago.

GALI, J. and MONACELLI, T. (2002). "Monetary Policy and Exchange Rate Volatility in a Small Open Economy", mimeo, National Bureau of Economic Research, Working Paper 8905, April. 
GERTLER, M., GILCHRIST, S. and NATALUCCI, F. (2001). "External Constraints on Monetary Policy and the Financial Accelerator", mimeo, New York University.

HAUSMANN, R. PANIZZA, U. and STEIN, E. (2001). "Why do Countries Float the Way they Float?", Journal of Development Economics, 66, 387-414.

HAUSMANN, R., GAVIN, M., PAGES-SERRA, C. and STEIN, E. (1999). "Financial Turmoil and the Choice of Exchange Rate Regime", mimeo, Inter-American Development Bank.

JEANNE, O. (2001). "Why do Emerging Economies Borrow in Foreign Currency?", mimeo, IMF.

KIYOTAKI, N. and MOORE, J. (1997) "Credit Cycles", Journal of Political Economy, 105, (2), 211-48.

KRUGMAN, P. (1999). "Balance Sheets, the Transfer Problem and Financial Crises", in International Finance and Financial Crises, P. Isard, A. Razin and A. Rose (eds.), Kluwer Academic Publisher.

KRUGMAN, P. and TAYLOR, L. (1978). "Contractionary Effects of Devaluation", Journal of International Economics, 8, 445-56.

LEVY-YEYATI, E. and STURZENEGGER, F. (2001). "To Float or to Trail: Evidence on the Impact of Exchange Rate Regimes", mimeo, Business School, Universidad Torcuato Di Tella.

LEVY-YEYATI, E. and STURZENEGGER, F. (2001). "Exchange Rate Regimes and Economic Performance", Business School, Universidad Torcuato Di Tella.

LEVY-YEYATI, E. and STURZENEGGER, F. (1999). "Classifying Exchange Rate Regimes: Deeds vs. Words", mimeo, Business School, Universidad Torcuato Di Tella.

MAGUD, N. (2003a). "Liability Dollarization, Openness, and Exchange Rate Regimes", mimeo, Department of Economics, University of Maryland.

MAGUD, N. (2003b). "Exchange Rate Regime Choice and Country Characteristics: an Empirical Investigation", mimeo, University of Maryland, Department of Economics, 2003.

MAGUD, N. (2001). "On Asymmetric Business Cycles and the Effectiveness of Counter-Cyclical Fiscal Policies", mimeo, University of Maryland at College Park.

MEADE, J. (1951). "The Balance of Payments", Oxford University Press, London.

MENDOZA, E. (2001). "Credit, Prices, and Crashes: Business Cycles with a Sudden Stop", mimeo, National Bureau of Economic Research, Working Paper 8338, June.

MENDOZA, E. (1995). "The Terms of Trade, the Real Exchange Rate, and Economic Fluctuations", International Economic Review, 36, (1), February, 101-37. 
MENDOZA, E. (1991). "Real Business Cycles in a Small Open Economy", American Economic Review, 81, (4), September, 797-818.

OBSTFELD, M. and ROGOFF, K. (1996). "Foundations of International Macroeconomics", Cambridge, Massachusetts, MIT Press.

REINHART, C. and ROGOFF, K. (2002). "The Modern History of Exchange Rate Arrangements: a Reinterpretation", mimeo, National Bureau of Economic Research, Working Paper 8963, June, forthcoming in Quarterly Journal of Economics, 2004.

SIMS, C. (1986). "Are Forecasting Models Usable for Policy Analysis?", Federal Reserve Bank of Minneapolis Quarterly Review, Winter, 3-16.

TORNELL, A. and WESTERMANN, F. (2002). "The Credit Channel in Middle Income Countries", mimeo, University of California, Los Angeles.

WOODFORD, M. (1996). "Control of the Public Debt: a Requirement for Price Stability?", mimeo, National Bureau of Economic Research, Working Paper 5684, July. 


\section{A Appendix}

\section{A.1 Uniqueness of Steady State}

In this section we show that there exists only one steady state as a function of parameters, thus permitting log-linearization around the steady state to analyze impulse response effects of "small" shocks. As already stated, all variables without a time subscript will be referred to the economy's steady state.

As noted above, we have assumed that $P_{t}^{F *}=1 \forall t$ and that $\frac{P^{H *}}{P F^{*}}=1$ in steady state. Also, there are no shocks to productivity in steady state, i.e. $A^{F}=A^{H}=1$. Then, $P^{H}=1$ and recalling (12) and (13), $\frac{P^{H}}{P^{F}}=1$, thus $P^{H}=P^{F}=S$. Consequently, $P^{T}=1$.

From (26) we obtain

$$
\frac{\alpha^{J} P^{J} Y^{J}}{Q^{J} K^{J}}=\iota \eta^{J}
$$

so that plugging in (A.1) and (24) into (29) we obtain that

$$
1=\delta^{J} \iota \eta^{J}
$$

i.e. $\eta^{J}=\left(\frac{1}{\delta^{J} \iota}\right)$, thus pinning down the risk premium for each sector in steady state. Note that a necessary condition for the gross risk premium to be greater than one in steady state is that $0<\delta^{J} \iota<1$.

Consequently, there is a unique leverage given by $\varpi=\frac{Q^{J} K^{J}}{P^{J} N^{J}}>1$, as (27) shows. ${ }^{24}$ Furthermore, plugging (A.2) into (A.1) one can show that $\frac{Q^{J} K^{J}}{P^{J} Y^{J}}=\alpha^{J} \delta<1$.

Since in steady state $Q^{J}=P^{J}$, then by inspection of (31) and (30) we observe that the only adjustment costs in steady state correspond to the depreciation rate, equal to one.

From (25) we notice that

$$
R^{J}=\frac{\alpha^{J} Y^{J}}{Q^{J} K^{J}}
$$

while from the optimization conditions of firms in each sector $R^{J}=\frac{\alpha^{J} P^{J} Y^{J}}{k^{J}}$, meaning that

$$
\frac{K^{J}}{Y^{J}}=\frac{\alpha^{J} P^{J}}{R^{J}}
$$

Combining (A.3) and (A.4) we can see that in steady state $\frac{K^{J}}{Y^{J}}=\frac{\alpha^{J}}{\delta^{J}}$. Consequently, by use of the resource constraint (32) we are able to characterize $\frac{C^{N}}{Y^{N}}=\frac{\delta^{J}-\alpha^{J}}{\delta^{J}}$.

For balance of payments to be in equilibrium in steady state, $X=C^{F}$, thus implying that

$$
\frac{C^{H}}{Y^{H}}=1-\frac{\alpha^{J}}{\delta^{J}}-C^{F}
$$

\footnotetext{
${ }^{24}$ That $\varpi>1$ can be observed by inspection of $(24)$.
} 
However, since $P^{H}=S=P^{F}=P^{T}=1$ in steady state, by use of (20) we notice that

$$
C^{F}=\frac{(1-\phi)}{\phi} C^{H}
$$

and plugging it into (9) one can show that $C^{H}=\phi C^{T}$; the latter, combined with (A.6) implies that $C^{F}=(1-\phi) C^{T}$.

On the other hand, from (19), and the obtained value for the consumption of home goods as a function of tradables in steady state, one can show that

$$
\frac{C^{H}}{C^{N}}=\frac{\gamma \phi}{1-\gamma}\left(P^{N}\right)^{\rho}
$$

Plugging (A.6) into (A.5), one obtains that

$$
\frac{C^{H}}{Y^{H}}=\frac{\delta^{J}-\alpha^{J}}{\delta^{J}} \phi
$$

which implies that

$$
\frac{X}{Y^{H}}=(1-\phi) \frac{\delta^{J}-\alpha^{J}}{\delta^{J}}
$$

Also, since in equilibrium wages paid in each sector should equal each other, $W^{H}=W^{N}$. By combining (21) and (22), which results in $\frac{L^{H}}{L^{N}}=\frac{1-\phi}{\phi}$, with the budget constraint (18) we obtain

$$
\frac{W^{N} L^{N}}{P C}=\psi
$$

and

$$
\frac{W^{H} L^{H}}{P C}=1-\psi
$$

Looking at (30) we notice that in steady state $\Phi()=$.1 , thus pinning down the capital stock in steady state.

Finally, since there is only one level of leverage in steady state in each sector and there is a unique $\frac{K^{J}}{Y^{J}}$, we can obtain a unique $\frac{N^{J}}{Y^{J}}$ ratio and thus a unique $\frac{B^{J}}{Y^{J}}$ as well.

\section{A.2 Log-linear Approximation}

\section{A.2.1 The Linearized Model}

The dynamics of the model are analyzed by observing the evolution of the variables around the steady state when hit by a "small" shock. In order to do so, and given the fundamental non-linearity of the model, we firstly log-linearize it around the steady state. In what follows, all variables without a time subscript will refer to the economy's steady state, whereas lower case letters represent the percentage deviation of each variable from its steady state value. The model described above can 
be characterized by the following set of equations, which for ease of tractability, is separated into 6 blocks: demand, supply, resource constraints, labor market equilibrium, evolution equations and policy regimes.

Demand

$$
\begin{gathered}
c_{t}=\Omega_{H} c_{t}^{H}+\Omega_{F} c_{t}^{F}+\Omega_{N} c_{t}^{N} \\
p_{t}=\Gamma_{H} p_{t}^{H}+\Gamma_{N} p_{t}^{N}+\Gamma_{s} s_{t} \\
c_{t}+p_{t}=E_{t}\left[p_{t+1}+c_{t+1}\right] \\
\Lambda_{H} c_{t}^{H}+\Lambda_{F} c_{t}^{F}-c_{t}^{N}=\rho p_{t}^{N}-\rho \phi p_{t}^{H}-\rho(1-\phi) s_{t} \\
c_{t}^{F}-c_{t}^{H}=\varsigma\left(p_{t}^{H}-s_{t}\right) \\
p_{t}^{H}-s_{t}=p_{t}^{H *} \\
p_{t}+c_{t}=\left(\frac{W^{N} L^{N}}{P C}\right) l_{t}^{N}+\left(\frac{W^{N} L^{N}}{P C}\right) w_{t}^{N}+\left(\frac{W^{H} L^{H}}{P C}\right) l_{t}^{H}+\left(\frac{W^{H} L^{H}}{P C}\right) w_{t}^{H}
\end{gathered}
$$

\section{Supply}

$$
\begin{gathered}
y_{t}^{H}=a_{t}^{H}+\alpha^{H} k_{t-1}^{H}+\left(1-\alpha^{H}\right) l_{t}^{H} \\
y_{t}^{N}=a_{t}^{N}+\alpha^{N} k_{t-1}^{N}+\left(1-\alpha^{N}\right) l_{t}^{N} \\
\eta_{t}^{H^{\prime}}=E_{t}\left[y_{t+1}^{H}+p_{t+1}^{H}-s_{t+1}\right]-q_{t}^{H}-k_{t}^{H}+s_{t}-\iota_{t}^{\prime} \\
\eta_{t}^{N^{\prime}}=E_{t}\left[y_{t+1}^{N}+p_{t+1}^{N}-s_{t+1}\right]-q_{t}^{N}-k_{t}^{N}+s_{t}-\iota_{t}^{\prime} \\
\eta_{t}^{H^{\prime}}=\mu\left[q_{t}^{H}+k_{t}^{H}-p_{t}^{H}-n_{t}^{H}\right]
\end{gathered}
$$




$$
\eta_{t}^{N^{\prime}}=\mu\left[q_{t}^{N}+k_{t}^{N}-p_{t}^{N}-n_{t}^{N}\right]
$$

\section{Resource Constraints}

$$
\begin{gathered}
y_{t}^{H}=\left(\frac{C^{H}}{Y^{H}}\right) c_{t}^{H}+\left(\frac{K^{H}}{Y^{H}}\right) k_{t}^{H}+\left(\frac{X}{Y^{H}}\right) x_{t} \\
y_{t}^{N}=\left(\frac{C^{N}}{Y^{N}}\right) c_{t}^{N}+\left(\frac{K^{N}}{Y^{N}}\right) k_{t}^{N}
\end{gathered}
$$

\section{Evolution Equations}

$n_{t}^{H}=\varpi\left(y_{t}^{H}+q_{t-1}^{H}\right)+\varpi \Psi^{H} \eta\left(\eta_{t-1}^{H^{\prime}}+y_{t}^{H}\right)+(1-\varpi)\left(s_{t}-p_{t}^{H}+\iota_{t-1}^{\prime}+\eta_{t-1}^{H^{\prime}}-s_{t-1}\right)-\varpi\left(q_{t-1}^{H}+k_{t-1}^{H}\right)+p_{t-1}^{H}+n_{t-1}^{H}$

$n_{t}^{N}=\varpi\left(y_{t}^{N}+q_{t-1}^{N}\right)+\varpi \Psi^{N} \eta\left(\eta_{t-1}^{N^{\prime}}+y_{t}^{N}\right)+(1-\varpi)\left(s_{t}-p_{t}^{N}+\iota_{t-1}^{\prime}+\eta_{t-1}^{N^{\prime}}-s_{t-1}\right)-\varpi\left(q_{t-1}^{N}+k_{t-1}^{N}\right)+p_{t-1}^{N}+n_{t-1}^{N}$

$$
\begin{aligned}
& q_{t}^{H}-p_{t}^{H}=-\varphi\left(k_{t}^{H}-k_{t-1}^{H}\right) \\
& q_{t}^{N}-p_{t}^{N}=-\varphi\left(k_{t}^{N}-k_{t-1}^{N}\right)
\end{aligned}
$$

Labor Market Equilibrium

$$
\begin{gathered}
\left(y_{t}^{N}+p_{y}^{N}\right)-\left(y_{t}^{H}+p_{t}^{H}\right)=\frac{1+v}{v}\left(l_{t}^{H}-l_{t}^{N}\right) \\
(1+\beta) w_{t}^{H}-\lambda l_{t}^{H}=w_{t-1}^{H}+\beta E_{t}\left[w_{t+1}^{H}\right] \\
(1+\beta) w_{t}^{N}-\lambda l_{t}^{N}=w_{t-1}^{N}+\beta E_{t}\left[w_{t+1}\right]
\end{gathered}
$$




\section{Policy Regimes}

$$
s_{t}=0
$$

for fixed exchange rate regimes or

$$
p_{t}=0
$$

for a flexible exchange rate. ${ }^{25}$

Finally, the stochastic processes are assumed to be $A R(1)$, with persistent coefficients $\xi_{r}$ for $r=\iota, p_{t}^{H *}, a_{t}^{H}, a_{t}^{N}, x_{t}$ :

$$
\begin{gathered}
\iota_{t}^{\prime}=\xi_{\iota} \iota_{t-1}^{\prime}+\nu_{\iota} \\
p_{t}^{H *}=\xi_{p^{H *}} p_{t-1}^{H *}+\nu_{p^{H *}} \\
a_{t}^{H}=\xi_{a^{H}} a_{t-1}^{H}+\nu_{a^{H}} \\
a_{t}^{N}=\xi_{a^{N}} a_{t-1}^{N}+\nu_{a^{N}} \\
x_{t}=\xi_{x} x_{t-1}+\nu_{x}
\end{gathered}
$$

in which $\nu_{r}$ represent i.i.d. processes, and where

$$
\begin{gathered}
\Omega_{H}=\gamma^{\frac{1}{\rho}}\left(\frac{C^{T}}{C}\right) \phi^{\frac{1}{\varsigma}}\left(\frac{C^{H}}{C^{T}}\right)^{\frac{\varsigma-1}{\varsigma}} \\
\Omega_{F}=\gamma^{\frac{1}{\rho}}\left(\frac{C^{T}}{C}\right)(1-\phi)^{\frac{1}{\varsigma}}\left(\frac{C^{F}}{C^{T}}\right)^{\frac{\varsigma-1}{\varsigma}} \\
\Omega_{N}=(1-\gamma)^{\frac{1}{\rho}}\left(\frac{C^{N}}{C}\right)^{\frac{\rho-1}{\rho}} \\
\Gamma_{H}=\gamma\left(\frac{P^{T}}{P}\right)^{1-\rho} \phi
\end{gathered}
$$

\footnotetext{
${ }^{25}$ For our purposes, these are exogenous processes. On the contrary, Gertler, Gilchrist and Natalucci (2001) deal with endogenous regimes, through Taylor rules; Gali and Monacelli (2002), also focus on endogenous regimes but without the existence of financial frictions.
} 


$$
\begin{gathered}
\Gamma_{s}=\gamma\left(\frac{P^{T}}{P}\right)^{1-\rho}(1-\phi) \\
\Gamma_{N}=(1-\gamma)\left(\frac{P^{N}}{P}\right)^{1-\rho} \\
\lambda=\left[\frac{1-\beta \theta}{1+\frac{\epsilon-1}{1-\kappa}}\right]\left[\frac{\epsilon(1-\theta)}{\theta}\right] \\
\varpi=\frac{Q K}{P N} \\
\Lambda_{H}=\phi^{\frac{1}{\varsigma}}\left(\frac{C^{H}}{C^{T}}\right)^{\frac{\varsigma-1}{\varsigma}} \\
\Lambda_{F}=(1-\phi)^{\frac{1}{\varsigma}}\left(\frac{C^{F}}{C^{T}}\right)^{\frac{\varsigma-1}{\varsigma}}
\end{gathered}
$$

where $\iota_{t}^{\prime}$ and $\eta_{t}^{J^{\prime}}$ represent the log-linear deviations from steady state of $\iota_{t}$ and $\eta_{t}^{J}$, respectively.

Equation (A.12) represents the linearized version of the aggregate consumption composite (8), once the composite for tradables (9) has been incorporated. (A.13) comes from substituting (11) into (10) and then computing the log-linear approximation. (A.13) represents the composite price index given the price of home goods, foreign goods and non-tradable goods, after taking into account that the international price of foreign goods is constant and equal to one, thus implying that the price of foreign goods equals the nominal exchange rate in every period. (A.15) results from the optimality conditions for demand of the three goods in the economy given relative prices. It is obtained after substituting (9) and (11) into (19), and shows how each of the relative demands for foreign, home and non-tradable goods, negatively depend on their relative prices. Regarding (A.16), it depicts the log-linear version of (20), thus displaying the negative relation with respect to prices that in equilibrium should be observed regarding the consumption of the two type of tradable goods. PPP is represented by (A.17), which comes from (12), in that the domestic price of home goods must be equal to the exchange rate plus the international price of the good.

Production functions for home and non-tradable goods, respectively, are given by (A.19) and (A.20), and reflect each sector's production function (1). In each sector, output could be affected by total factor productivity shocks, $a_{t}^{H}$ and $a_{t}^{N}$ respectively; in order to produce output, capital and labor are required.

Resource constraints are given by (A.25) and (A.26) for home goods and non-tradable goods and represent (33) and (32), respectively. Non-tradable goods can either be consumed or used to produce capital. Home goods can also be exported for the consumption of the rest of the world.

Financial frictions are observed in (A.21) and (A.22) for home and non-tradable sectors, respec- 
tively, corresponding to (26). The risk premium in excess of the riskless international interest rate that firms in each sector pay, in equilibrium, should equal the expected rate of return on capital purchased today that will be used to produce tomorrow.

The mentioned external finance premium takes a functional form that is increasing in the entrepreneur's leverage in each sector, as in (27). Specifically, the external finance premium increases with the ratio of acquired capital to the entrepreneur's net worth, i.e. leverage. Thus this risk premium increases, all else equal, if either the real value of capital or its price increase, but drops when each sector's price and/or real net worth increase, thus reflecting the ability of entrepreneurs to repay their debts. Notice that the elasticity of the risk premium with respect to its leverage is assumed to be constant only in steady state, and is given by $\mu$. The log-linear versions are (A.23) and (A.24), respectively.

(A.27) and (A.28) are log-linearized counterparts of (29) for each sector, after (24) is taken into account for ease of tractability, and reflect the temporal evolution of net worth. Notice that, as shown for the steady state of the economy, $\varpi>1$. This implies that net worth increases more than proportionally with output and the sector's output price, but decreases with the exchange rate, the riskless international interest rate and the risk premium. Also, net worth increases with the previous period's net worth and sectoral output price, as well as with a higher value of capital from the pervious period, that in turn can arise from an increase in the level of capital and/or its price.

The usual capital adjustment equations in the Dynamic New Keynesian literature derived from (31) determine the price of capital in each sector, as well as the production function for capital. This is reflected in (A.29) and (A.30), respectively. It denotes the effects on the price of capital generated by movements in the capital stock in each sector -recall that we have assumed that capital is sector-specific- and the dimension of that effects is given by the elasticity $\varphi$, which is assumed to be constant in steady state only.

For equilibrium in the labor market, optimally chosen labor supply must be equal to labor demand in each sector. Expression (A.31) displays the mentioned equilibrium. It is the result of relative labor supply given by jointly considering (21) and (22), as well as labor demand, characterized by (6).

Consumers' budget constraint (18) should also be taken into account, as is depicted in (A.18), binding total consumption according to total wage income.

Notice that (A.32) and (A.33) represent the evolution of sticky wages. Within each sector during period $t$ only a fraction $(1-\theta)$ of workers are allowed to change their wages for given demand, as in the typical Calvo (1983) scheme. The wage decision mechanism considers past wages as well as expected future wages given available information. This generates a forward-looking Phillips curve. (A.32) and (A.33) result from (14).

Finally, either (A.34), the fixed exchange rate regime, or (A.35), the flexible exchange rate regime, characterize the policy regime. Each of them is considered in turn, depending on the exchange rate regime being analyzed. 
To conclude, (A.36)-(A.40) represent the stochastic exogenous processes out of which the shocks arise. As can be observed, all of the them are assumed, in principle, to be $A R(1)$ processes, unless specifically stated.

Notice that the remaining constants directly depend on steady state values of endogenous variables, as well as parameters.

\section{A.2.2 Parameter Values and Steady State}

In this section we lay out the basic parameter values used to calibrate the economy's steady state. It is important to remark that this is not intended to be a strict calibration exercise, but simply a theoretical tool to try to shed some light on the issue at hand and to analyze the implications of the model. In this regard, most of the parameter values are taken either from data or extracted from the exiting quantitative literature.

Preferences: Following Gertler, Gilchrist and Natalucci (2001), the intratemporal elasticity of substitution in consumption between tradables and non-tradables, $\rho$, equals 2 , and the elasticity of substitution in consumption between home and foreign goods, $\varsigma$ is also equal to 2 . The share of tradables in total consumption, $\gamma$, equals 0.5 , while the share of home goods in total tradables is assumed to be $\phi=0.8$. The quarterly discount factor $\beta$ is assumed to be equal to 0.9615 , thus generating an international yearly riskless interest rate of $4 \%$, consistent with most of the existent quantitative models. To represent a high degree of pass-through, we assume that the contribution to the price index of tradable goods equals $60 \% .{ }^{26}$ As is standard in the Dynamic New Keynesian literature, we assume that the proportion of individuals that can change their wage in each period, $\theta$, is 0.75 . Finally, $\epsilon$ equals 3 while the scale parameter $\kappa$ is assumed to be 0.6 .

Technology: We assume that the home goods sector is relatively more capital intensive than the non-tradable sector by imposing that $\alpha^{H}=0.32$ and that $\alpha^{N}=0.20$, where $\alpha^{J}$ is the share of capital in output for sector $J=H, N$. Also, the share of labor income obtained in the non-tradable sector, $\psi$, is assumed to equal 0.364, as in Mendoza (2001). Regarding the capital production technology, we follow Bernanke, Gertler and Gilchrist (2000) by considering that $\varphi$, the price elasticity of capital, equals 0.25 .

Entrepreneurs: $\delta^{H}$, the proportion of income that entrepreneurs devote to investment is assumed to be 0.98 , while $\delta^{N}$ equals 0.90 . This is to generate differentiated external finance premiums in steady state for each sector. The steady state external finance premium paid by home entrepreneurs, $\eta^{H}$, is $1 \%$, while the steady state external finance premium for entrepreneurs in the non-tradable sector, $\eta^{N}$, equals $10 \%$. The rationale for this is that since non-tradables, by its own nature, only sell domestically and do not have the chance to re-direct their sales towards the rest of the world, they are by definition riskier credit subjects than entrepreneurs that invest in home tradables. The former obtain their profits in domestic currency while their debt is denominated in foreign currency. Entrepreneurs in the tradable sector, given they have the chance to export are less exposed to the

\footnotetext{
${ }^{26}$ Robustness checks show this assumption to be inessential, only helping for expositional purposes.
} 
mentioned currency mismatch, thus pay a lower premium in steady state. Furthermore, given the one-to-one relationship between risk premium and leverage in steady state, non-tradables will have a higher leverage in steady state than tradables. ${ }^{27}$ For our purposes, then, leverage in steady state will equal 3.2 for home-sector and 1.2 for non-tradables. ${ }^{28}$ Furthermore, the elasticity of the risk premium in steady state is assumed to 3.2 for entrepreneurs in the home sector, while only 1.7 for the ones in the non-tradables'. ${ }^{29}$

\begin{tabular}{ccc}
\hline Parameter & Description & Value \\
\hline$\rho$ & intratemp. elasticity of substit. T-NT & 2 \\
$\varsigma$ & intratemp. elasticity of substit. H-F & 2 \\
$\gamma$ & share of tradables in total consumption & 0.5 \\
$\phi$ & share of home goods in total tradables & 0.8 \\
$\beta$ & quarterly discount factor & 0.9615 \\
$\frac{P^{T}}{P}$ & contribution to the price index of tradable goods & 0.6 \\
$\theta$ & prop.indiv. that can change their wage in each period & 0.75 \\
$\epsilon$ & & 3 \\
$\kappa$ & scale parameter & 0.6 \\
$\alpha^{H}$ & share of capital to output for sector H & 0.32 \\
$\alpha^{N}$ & share of capital to output for sector N & 0.20 \\
$\psi$ & share of labor income from NT & 0.364 \\
$\varphi$ & price elasticity of capital & 0.25 \\
$\delta^{H}$ & prop. income entrep. devote to investment in H & 0.98 \\
$\delta^{N}$ & proportion of income that entrepreneurs devote to investment in NT & 0.90 \\
$\varpi^{H}$ & leverage in H & 3.2 \\
$\varpi^{N}$ & leverage in N & 1.2 \\
$\mu^{H}$ & elasticity of the risk premium in H & 3.2 \\
$\mu^{N}$ & elasticity of the risk premium in N & 1.7 \\
\hline
\end{tabular}

Table A.I: Steady state parameter values for simulations.

\begin{tabular}{ccc}
\hline$r$ & international yearly riskless interest rate & 0.04 \\
$\eta^{H}$ & risk premium in $\mathrm{H}$ & 0.01 \\
$\eta^{N}$ & risk premium in N & 0.10 \\
$\frac{K^{H}}{Y^{H}}$ & capital output ratio $\mathrm{H}$ & 0.326 \\
$\frac{K^{N}}{Y^{N}}$ & capital output ratio N & 0.180 \\
$\frac{C^{H}}{Y^{H}}$ & H consumption to output ratio & 0.60 \\
$\frac{C^{N}}{Y^{N}}$ & N consumption to output ratio & 0.82 \\
$\frac{X}{Y^{H}}$ & exports to home-sector output ratio & 0.068 \\
\hline
\end{tabular}

Table A.II: Implied steady state values.

These parameter values imply that in steady state, the capital-output ratio, $\frac{K^{J}}{Y^{J}}$ for $J=H, N$, will equal 0.326 in the tradable sector and 0.18 in the non-tradable sector. Also, they result in

\footnotetext{
${ }^{27}$ This should be reflected in the debt contract.

${ }^{28}$ This values are chosen for expositional purposes. When we check for robustness, the qualitative results are not altered for different values of these parameters.

${ }^{29}$ Again, we check for robustness and the qualitative results are not modified.
} 
consumption to output ratios, $\frac{C^{J}}{Y^{J}}$ of 0.60 for home goods and 0.82 for non-tradables. Notice that these values are approximately in line with those in Mendoza (2001). Finally, the parameters imply that in steady state the exports to home-sector output ratio, $\frac{X}{Y^{H}}$, will equal 0.068 in steady state.

Regarding the stochastic shock processes, we assume that the all of them follow an $A R(1)$ process with autocorrelations coefficients given by $\xi_{a^{H}}=\xi_{a^{N}}=\xi_{x}=0$, for the purpose of this exercise, while we take $\xi_{p^{H *}}=0.45$ in line with Mendoza (1995) estimates of the autocorrelation coefficient for terms of trade shocks in LDC's. Furthermore, this figure arises as a result of looking at the persistence of the residuals for the terms of trade series. Also, from these residuals, it was found that a shock of one standard deviation corresponds to a drop in terms of trade in the 5\%-15\% range. 


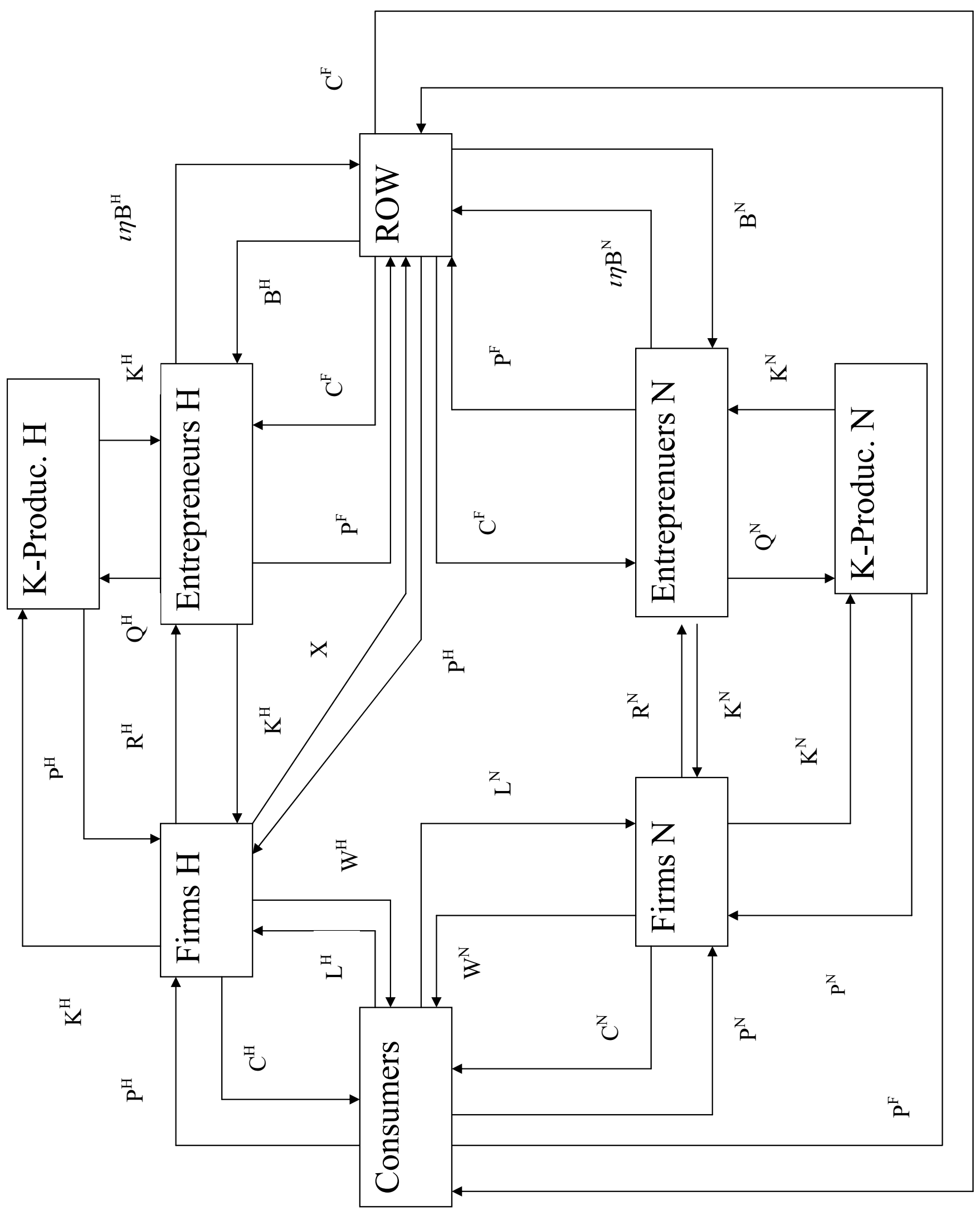

Figure A.I: Economy's interactions 